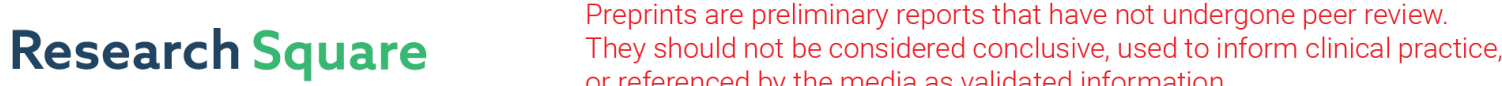 or referenced by the media as validated information. \\ Dynamic Behavior of Coal Pillar Under Different Load Percentage by Numerical Simulation
}

Guo-wei Dong ( $\square$ leng285@163.com )

XUST: Xi'an University of Science and Technology https://orcid.org/0000-0001-6311-8530

Hai-yang Liu

XUST

Guang-an Zhu

XUST: Xi'an University of Science and Technology

Research

Keywords: coal pillar, strain damage softening, load percentage, dynamic behavior, numerical simulation

Posted Date: September 8th, 2020

DOI: https://doi.org/10.21203/rs.3.rs-68745/v1

License: (1) This work is licensed under a Creative Commons Attribution 4.0 International License.

Read Full License 


\title{
Dynamic behavior of coal pillar under different load percentage by numerical simulation
}

\author{
Guo-wei Dong(董国伟) ${ }^{1}$,Hai-yang Liu(刘海洋) ${ }^{1}$,Guang-an Zhu(朱广安) ${ }^{1}$ \\ ${ }^{1}$ School of Energy Engineering, Xi'an University of Science and Technology, Xi'an, Shaanxi 710054, China
}

\begin{abstract}
The stability and dynamic response of coal pillar is of great importance in underground coal mining. In this paper, a series of uniaxial compressiveexperimentswerefirst carried out to investigate the mechanical properties of coal. Subsequently, a statistical constitutive damage model for coal was proposed and applied to the numerical simulation. The proposed strain damage softening function showed almostthe same goodness-of-fit on the experimental curve. A numericalmodel $\mathrm{FLAC}^{3 \mathrm{D}}$ was created to investigate the dynamic behavior of the coal pillar under different load percentage(LD). Modelling suggests that the incident and transmitted wave stress evolution observesa similar rule and its process can be divided into three stages, namely, static preload, dynamic disturbance and stabilized stages.Under the same load percentage, the peak incident and transmitted wave stress increase with the increase of dynamic disturbance intensity. On the contrary, the attenuation decrease. It is also observed that the failure zone interior the coal can be predicted by the wave propagation.
\end{abstract}

Keywords:coal pillar, strain damage softening, load percentage, dynamic behavior, numerical simulation

\section{Introduction}

Rock bursts, which are sudden dynamic disasters induced by deformation and fracture of the coal-rock mass, pose a serious threat to the production and safety of underground coal mining throughout the word[1-2]. Pillar burst is one of the typical types of rock burst called strain burst, which is caused by violent fracturing of intact rock and, in many cases, occurs in the vicinity of mining openings or pillars[3-4].

Practice and studies have shown that both the pillar and hard roof will accumulate a large amount of energy, a dynamic response is easily induced in the surrounding coal and rock mass, which will be serve under their coupling effect. In the mining areas of Shaanxi, Inner Mongolia and Xinjiang in West China, many rock burst accidents with huge energies have occurred under the conditions of wide coal pillar and hard roof [5-6].

Coal pillars play a key role in underground coal mines, which are left to provide support to the overlying strataand control surface subsidence,such as in thebord and pillar mining method, the strip mining method, etc. The coal pillar strength has been a focus of research for many years. Traditionally, the coal pillars design is considered in terms of the relationship between width $(w)$ and height $(h)$ of the pillar.Based on databases of actual coal mine pillars, many Empirical and theoreticalformulas related to the width-to-height ratio were developed by Salamon[7] 
and Galvin[8].Numerous authors have tried toquantify coal pillar strength using analytical approaches, numerical models and field measurements [9-12].However, the above researchesseldom take into account the material properties in their estimations, so their applications have limitations.

Numerical simulation, provides us with an opportunity to include a good number of relevant factors in the analysis so that the results may be more realistic. Furthermore,the effects of single factors can be easily studied numerically, whichis helpful to identify the most important factors for use in practice.Previous studies of this kind have proven the validity of the method[13-15].Jaiswal and Shrivastva [13] proposed an approach for estimation of strain-softening constitutive behavior of coal-mass through calibration of a numerical model with field cases, which considering various permutation and combination of strain-softening parameters. Wang et al [14] presented a numerical investigation on the dynamic mechanical state of a coal pillar, the results show that the intact core of the coal pillar plays a significant role in its loading capacity, i.e., the wider the coal pillar, the greater the volume of the elastic core. Poulsen et al [15] estimated the pillar strength in both dry and saturated conditions by numerical methods, and found that the pillar strength with saturation is approximated by weighting the pillar lithological component.

However, the determination of dynamic behavior of coal pillar under different LD is less widely reported in the literature. Therefore, the dynamic stress evolution is a topic of this study. In contrast to laboratory experiments and empirical method, numerical simulation is capable of capturing the stress state and damage evolution in coal mass and is therefore helpful in clarifying the associated coal failure mechanism under static combined with dynamic condition [16].

This paper presents a study on the coal pillar strength and dynamic behavior of the coal pillar under different load percentage. The arrangement is listed as follows: in Section 2 a series of experimental tests was carried out and in section 3 a statistical constitutive damage model for coal was derived. In sections 4 and 5, the preparation of this numerical study and the comparison between experimental and numerical results will be firstly conducted. Subsequently, dynamic behavior of the coal pillar under different LD will be investigated.

\section{Prior work}

Before starting to develop the numerical models, a series of tasks and tests had to be carried out to characterize the coal mass.Experimental samples were taken from coal seam No.5 of the 2130 Coal Mine in Xinjiang Province, China. At the beginning of the experiment, we cut the samples into cuboid specimens. All the specimens were about $50 \mathrm{~mm}$ long, $50 \mathrm{~mm}$ wide, and $100 \mathrm{~mm}$ high. Details of the specimen properties of the tests 
carried out are shown in Table 1.

Table1.Results of uniaxial compressive strength test in coal.

\begin{tabular}{c|c|c|c|c|c|}
\hline Sample NO. & $\begin{array}{c}\text { Density/ } \\
\left(\mathrm{g} / \mathrm{cm}^{3}\right)\end{array}$ & $\begin{array}{c}\text { Failure load/ } \\
\mathrm{kN}\end{array}$ & $\begin{array}{c}\text { Compression strength/ } \\
\mathrm{MPa}\end{array}$ & $\begin{array}{c}\text { Young's modulus/ } \\
\mathrm{GPa}\end{array}$ & $\begin{array}{c}\text { Tensile strength/ } \\
\mathrm{MPa}\end{array}$ \\
\hline 1 & 1.37 & 20.25 & 7.57 & 0.62 & \\
\hline 2 & 1.42 & 22.12 & 8.42 & 0.55 & \multirow{2}{*}{0.41} \\
\hline 3 & 1.38 & 16.59 & 6.22 & 0.35 & \\
\hline Average value & 1.39 & 19.65 & 7.40 & 0.5 & \\
\hline
\end{tabular}

The overall stress-strain curves obtained from experiments are shown in Fig. 1. According to experimental studies, the average density, uniaxial compressive strength, elastic modulus, cohesion, friction angle and Poisson's ratio of the coal are $1.39 \mathrm{~g} / \mathrm{cm}^{3}, 7.4 \mathrm{MPa}, 0.5 \mathrm{GPa}, 1.5 \mathrm{MPa}, 45^{\circ}$ and 0.22 , respectively.

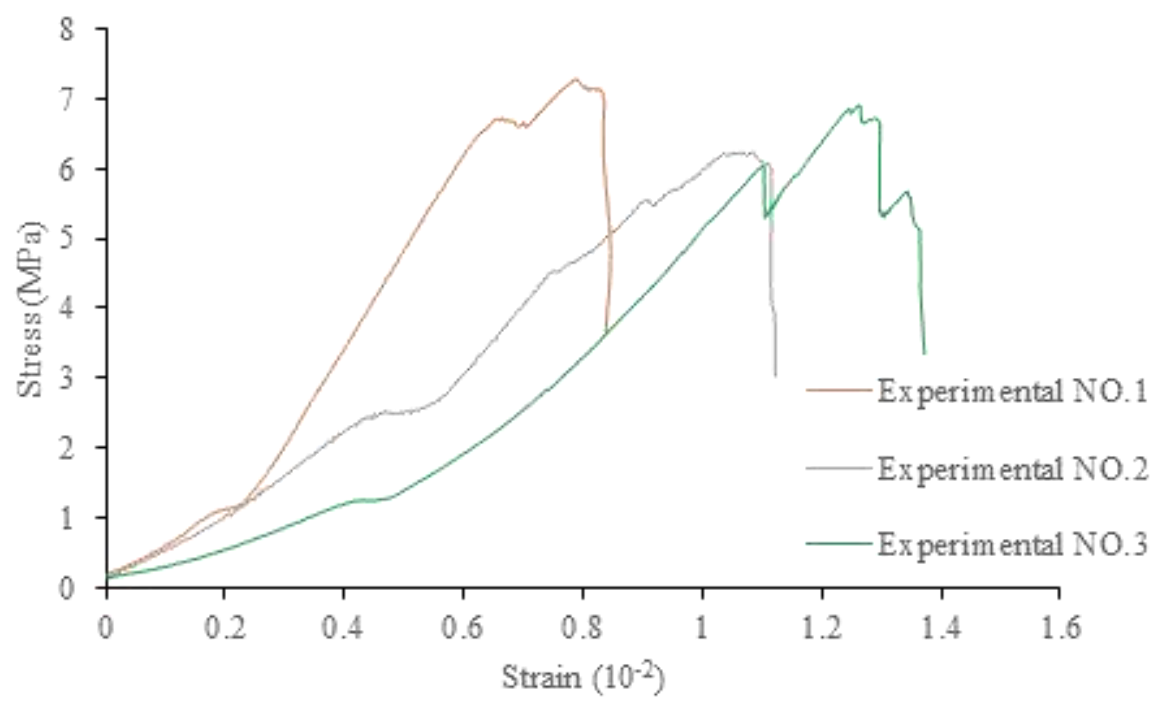

Fig. 1Full stress-strain curves of the coal specimens.

\section{Constitutive model analysis}

\subsection{Set up of constitutive model}

The coalspecimen has obvious heterogeneity and many defects exist in the interior. There is a big difference among the mechanical properties of the defects, and they are distributed randomly. The mechanical properties of these micro-unit are assumed to conform to a given Weibull distribution as defined by the following probability density function [17]:

$$
f(\varepsilon)=\frac{m}{F}\left(\frac{\varepsilon}{F}\right)^{m-1} \exp \left(-\left(\frac{\varepsilon}{F}\right)^{m}\right)
$$

where $\varepsilon$ is the mechanical parameter of the micro-unit (such as strength or Young's modulus); the scale parameter $F$ is related to the average of the micro-unit parameters and the parameter $m$ defines the shape of the distribution function.

According to the damage mechanics theory[18], the following constitutive relation can be obtained 


$$
\sigma=\sigma^{\prime}(1-D)=E \varepsilon(1-D)
$$

Assume $D$, the statistical damage variable, as the ratio of $c$, the number of damaged micro-units to $\mathrm{N}$, the number of all the micro-units. The damage variable $D$, which reflects the degree of internal damaged of the coal, ranges from 0 to 1 . Thus, the damage variable of the coal can be expressed as

$$
D=\frac{C}{N}=\frac{\int_{0}^{\varepsilon} C \varphi(x) d x}{N}=1-\exp \left(-\left(\frac{\varepsilon}{F}\right)^{m}\right)
$$

After substituting Eq. (3) into Eq. (2), we obtain the following equation

$$
\sigma=E \varepsilon(1-D)=E \varepsilon \exp \left(-\left(\frac{\varepsilon}{F}\right)^{m}\right)
$$

However, in the process of coal mass under compression, the effective area of normal and shear stress is the same after the destruction of the micro-unit, the damage variable of all the directions is $D$, and obtain [19]

$$
\sigma=E \varepsilon\left(1-C_{n} D\right)
$$

where $C_{n}$ is the damage proportional coefficient, ranges from 0 to 1 , which reflects the residual strength of coal.

$$
D=1-\exp \left[-\left(\frac{\varepsilon^{*}}{F}\right)^{m}\right]
$$

Substituting Eq.(5) into Eq.(4), We obtain the statistical model for damage in coal under uniaxial compression:

$$
\sigma=E \varepsilon\left(1-C_{n}\right)+E \varepsilon C_{n} \exp \left(-\left(\frac{\varepsilon}{F}\right)^{m}\right)
$$

For the softening constitutive model after the peak strength, the load-bearing capacity of the micro-units will reduce with increasing plastic strain,

$$
\begin{aligned}
& c=c_{0} \cdot\left(1-C_{n} D\right)=c_{0} \cdot\left\{1-C_{n}+C_{n} \cdot \exp \left[-\left(\frac{\varepsilon_{p}}{F}\right)^{m}\right]\right\} \\
& \tan \varphi=\tan \varphi_{0} \cdot\left(1-C_{n} D\right)=\tan \varphi \cdot\left\{1-C_{n}+C_{n} \cdot \exp \left[-\left(\frac{\varepsilon_{p}}{F}\right)^{m}\right]\right\}
\end{aligned}
$$

where $c_{0}$ and $\varphi_{0}$ represent the initial cohesion and friction angle of the micro-units, respectively.

\subsection{Discussion of model parameters and their physical meaning}

According to Eq. (8), the strain damage softening factor $C_{\mathrm{D}}$ is defined as follows: 


$$
C_{D}=1-C_{n} D=1-C_{n}+C_{n} \cdot \exp \left[-\left(\frac{\varepsilon_{p}}{F}\right)^{m}\right]
$$

Thestrain damage softening factor $C_{\mathrm{D}}$ reflects the damage softening degree of the material, and the physical meanings of the parameters are as follows:

(1) when the parameters $F$ and $m$ are constant, as shown in Fig. 2(a), with increase of $C_{\mathrm{n}}, C_{\mathrm{D}}$ decreases, i.e., the higher the $C_{\mathrm{n}}$, the higher the final softening degree of the material is. Therefore, the parameter $C_{\mathrm{n}}$ reflects the residual strength characteristics of coal and rock mass.

(2) when the parameters $F$ and $C_{\mathrm{n}}$ are constant, as shown in Fig. 2(b), the higher the $m$, the steeper the strain damage softening coefficient curve is, which indicates the higher the softening rate, the higher the brittleness. From the perspective of rock burst tendency, the faster the post peak softening rate is, the shorter the time required for dynamic failure of coal and rock mass, that is, the stronger the rock burst tendency is. Therefore, the parameter $C_{\mathrm{n}}$ reflects the brittlenessand rock burst tendency of coal and rock mass.

(3) when the parameters $m$ and $C_{\mathrm{n}}$ are constant, as shown in Fig. 2(c),with the increase of $F$, the decreasing section of strain damage softening coefficient curves shifts to the right part, i.e., the higher the $m$, the more plastic strain needs to enter the softening stage. Therefore, the parameter $F$ reflects the sensitivity of the material begins to softening.

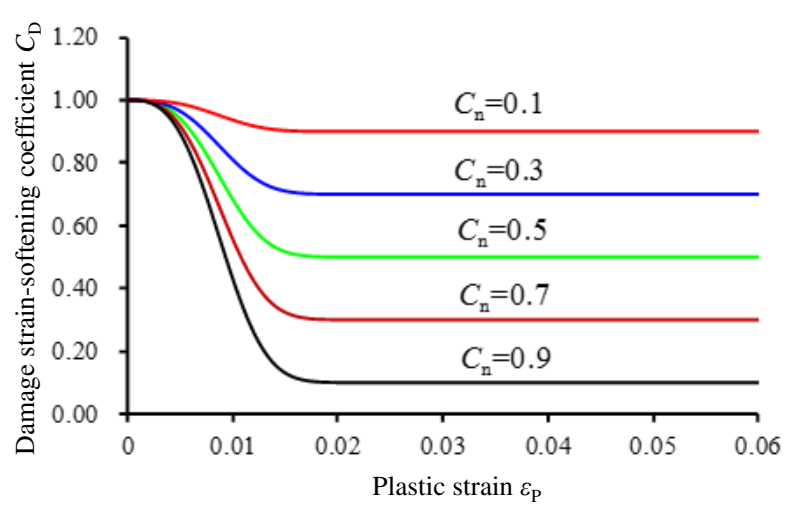

(a) $F=0.01, \quad m=3$

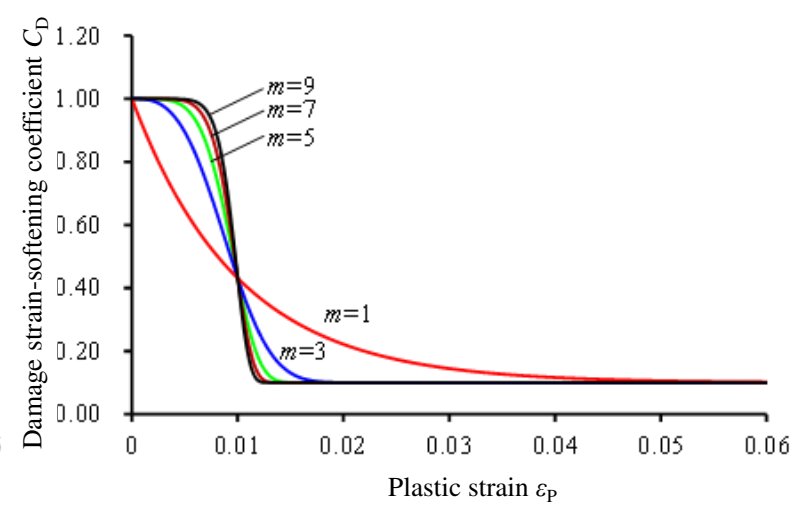

(b) $F=0.01, \quad C_{\mathrm{n}}=0.9$ 


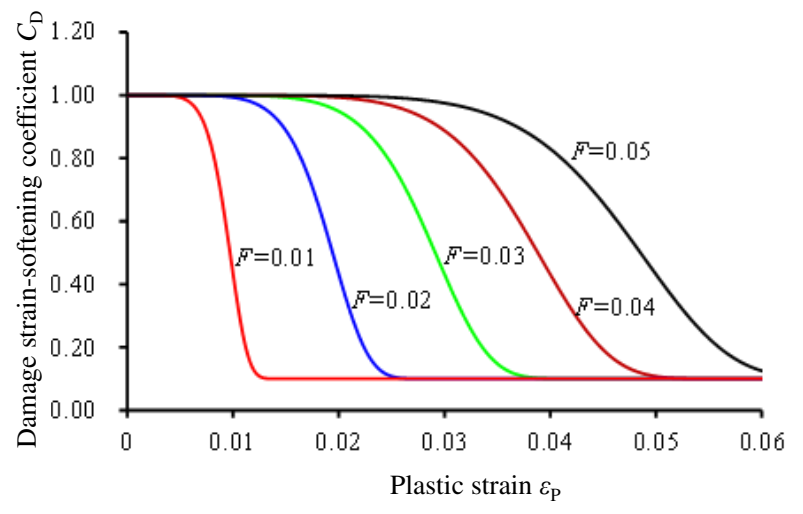

(c) $m=7, \quad C_{\mathrm{n}}=0.9$

Fig. 2Variation of the damage strain-softening coefficient $C_{\mathrm{D}}$ with the parameters of $C_{\mathrm{n}}, m$, and $F$ changing

\subsection{Physical experiment verification of the model}

It can be seen from Eq.(7) that the model parameters are determined by the following calculation methods:taking the parameters $E, F$, mand $C_{\mathrm{n}}$ as variables and adopting the optimization method, the objective function is established as follows

$$
\min \sum_{i=1}^{n}\left\{\sigma_{i}-\left\{E \varepsilon_{i}\left(1-C_{n}\right)+E \varepsilon_{i} C_{n} \exp \left[-\left(\frac{\varepsilon_{i}}{F}\right)^{m}\right]\right\}^{2}\right.
$$

wherenis the sample number of experimental data; $\sigma_{\mathrm{i}}$ and $\varepsilon_{\mathrm{i}}$ are the stress and strain of the $i$ th experimental data.

Coal samples are collected from Litang, Xuzhuang, Longgu, Zhangshuanglou coal mines, and Fig. 3 shows the comparison results of the above model calculation, literature calculation [20-21] and experimental results. It can be seen from the figure that the calculation model used in this paper is more reasonable than that in the literature, which can better fit the uniaxial stress-strain curve of coal and rock mass.

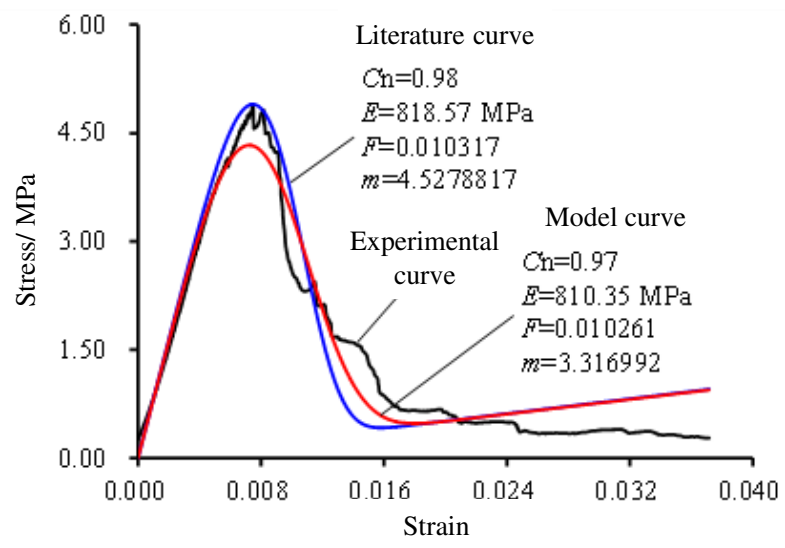

(a)coal sample 1

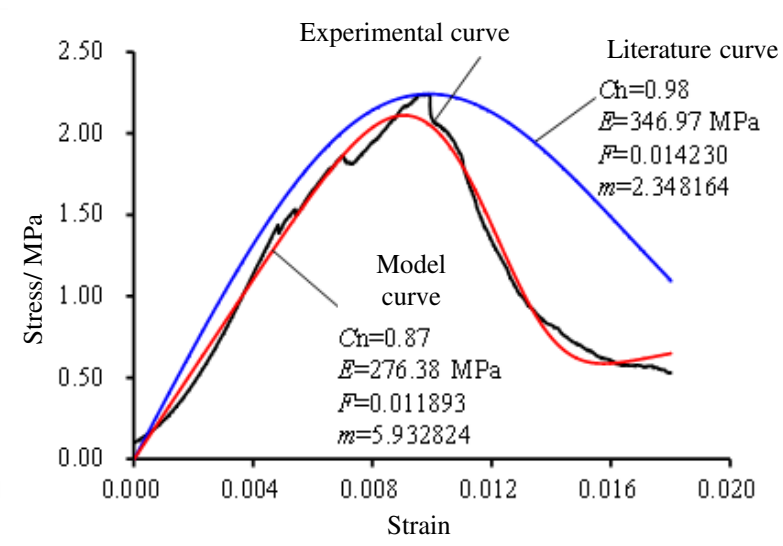

(b) coal sample 2 


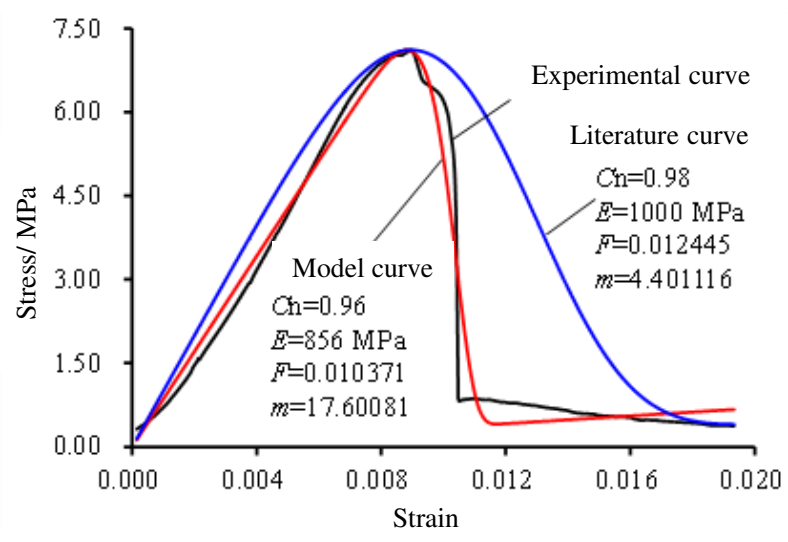

(c)coal sample 3

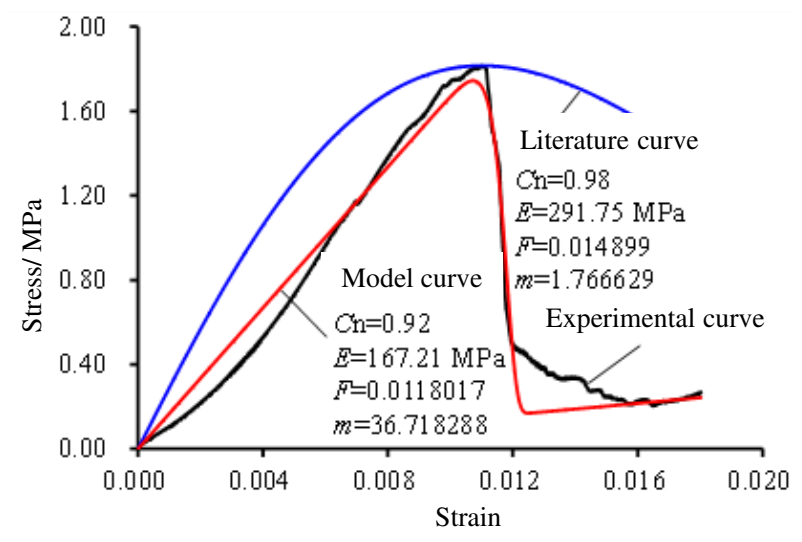

(d) coal sample 4

Fig. 3 Comparison between experimental curves and theoretical curves

\section{Numerical simulation}

Having obtained the strength properties of the coal, we shall now describe the working method followed in analyzing dynamic behavior of a coal pillar under different LD.

\subsection{Numerical model and failure criterion}

FLAC3D (Fast Lagrangian Analysis of Continua in 3Dimensions) [22] was employed to create a model of the coal pillar with dimensions of $50 \mathrm{~mm} \times 50 \mathrm{~mm} \times 100 \mathrm{~mm}$, the element size of pillar is kept constant as $2.5 \mathrm{~mm} \times$ $2.5 \mathrm{~mm} \times 2.5 \mathrm{~mm}$, ad shown inFig. 4.The chosen failure criterion is the strain softening modelin FLAC3D, in which the coal pillar was modeled as a non-linear strain-softening material with cohesion and friction angle softening as functions of the plastic strain (refer to Eq.(7)).

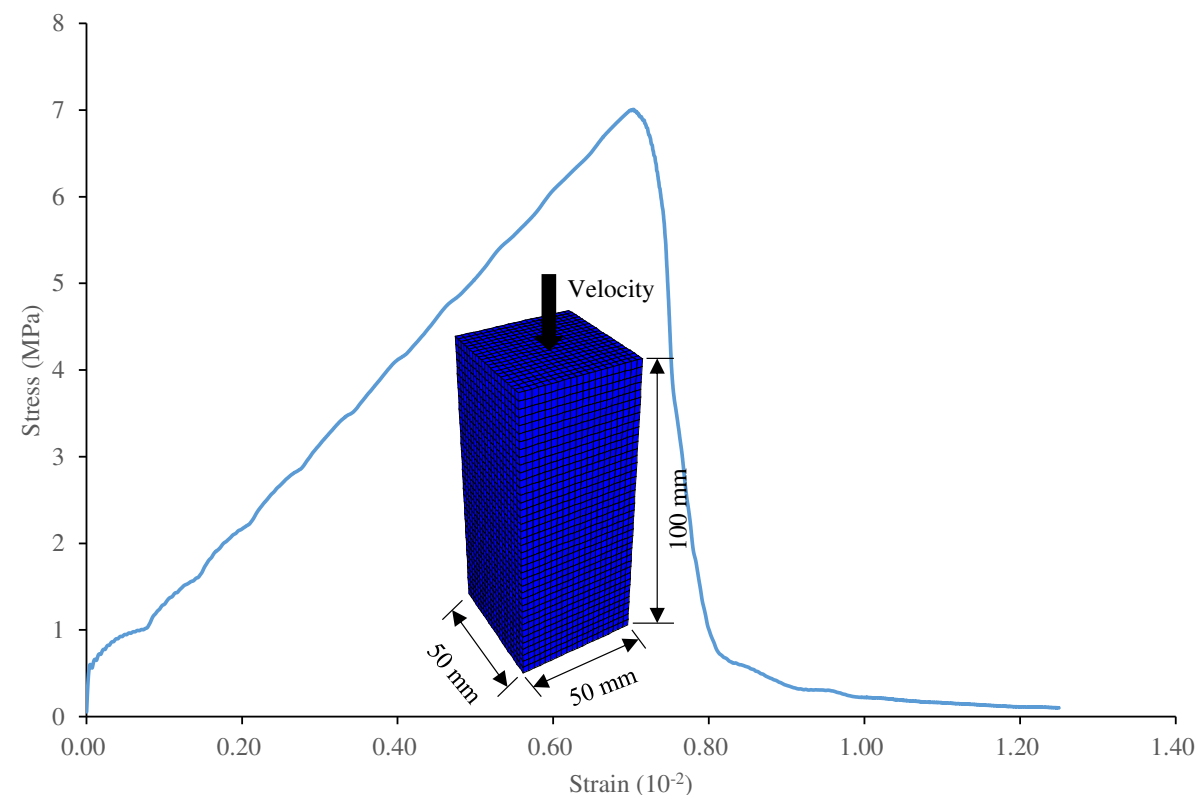

Fig. 4.A sketch of FLAC ${ }^{3 \mathrm{D}}$ mesh and the stress-strain curve of the numerical model.

\subsection{Boundary conditions of numerical model}

In order to obtain the condition of uniaxial compression, reasonable boundary conditions should be set around 
the numerical model, the displacement of four vertical symmetry planes of model is restricted in the normal direction. A constant velocity is applied to the top and bottom of the model in the z-direction to generate a vertical loading on this model. In this study, the magnitude of constant velocity has been set as $2.5 \times 10^{-7} \mathrm{~m} / \mathrm{s}$.

\subsection{Determination of relevant material parameters}

In this study, formula (6) was used to calibrate the material parameter for the model.The final calibration results gives a coal uniaxial compression strength (UCS) of 7.4 MPa and tensile strength is set as $0.41 \mathrm{MPa}$. Finally, after repeatedly verification and commission, the shape parameter $m$, the scale parameter Fand the damage proportional coefficient $\mathrm{C}_{\mathrm{n}}$ is set as $30,0.8$ and 0.002 , respectively.

\subsection{Dynamic disturbance}

As regards the combined static and dynamic loading conditions (as defined in Fig. 5.), the dynamic incident stress pulse $\mathrm{p}_{\mathrm{d}}(\mathrm{t})$, is applied at the top surface of a model domain after the static boundary stressesis applied. Under the dynamic loading condition, the bottom surface of the domain that has been restrained during the static loading is free from stress. The half-sine stress pulse (as defined in Fig. 5.) is used because this incident waveform is similar to the half-sine shape. For this waveform, two parameters (including amplitude ( $\left.\mathrm{p}_{\mathrm{dm}}\right)$ and duration ( $\left.\mathrm{t}_{\mathrm{dm}}\right)$ ) are involved in the numerical simulation in order to analyze dynamic behavior of the coal pillar under different LD.

According to the seismology theory, the P-wave of seismic source can be simplified as the superposition of sine waves in three directions perpendicular to each other in space. Therefore, the waveform used in the numerical simulation can be replaced by sine wave. At the same time, based on the statistics of experimental and field observation data, different mine tremors energy corresponds to different maximum amplitude of stress wave, and the specific corresponding relationship is shown in Table 2.

The statistical results show that when rock burst occurs, the energy level of mine tremor is generally $10^{5} \sim$ $10^{6} \mathrm{~J}$. According to the Table 2, the sine wave with the peak value of $30 \mathrm{MPa}$ can be selected as the dynamic load source. Therefore, in the numerical simulation, the vibration frequency of longitudinal stress wave is set as $50 \mathrm{~Hz}$ (the corresponding vibration period is $0.02 \mathrm{~s}$ ), the peak stress is $30 \mathrm{MPa}$, and the monitoring time is $1.2 \mathrm{~s}$. 


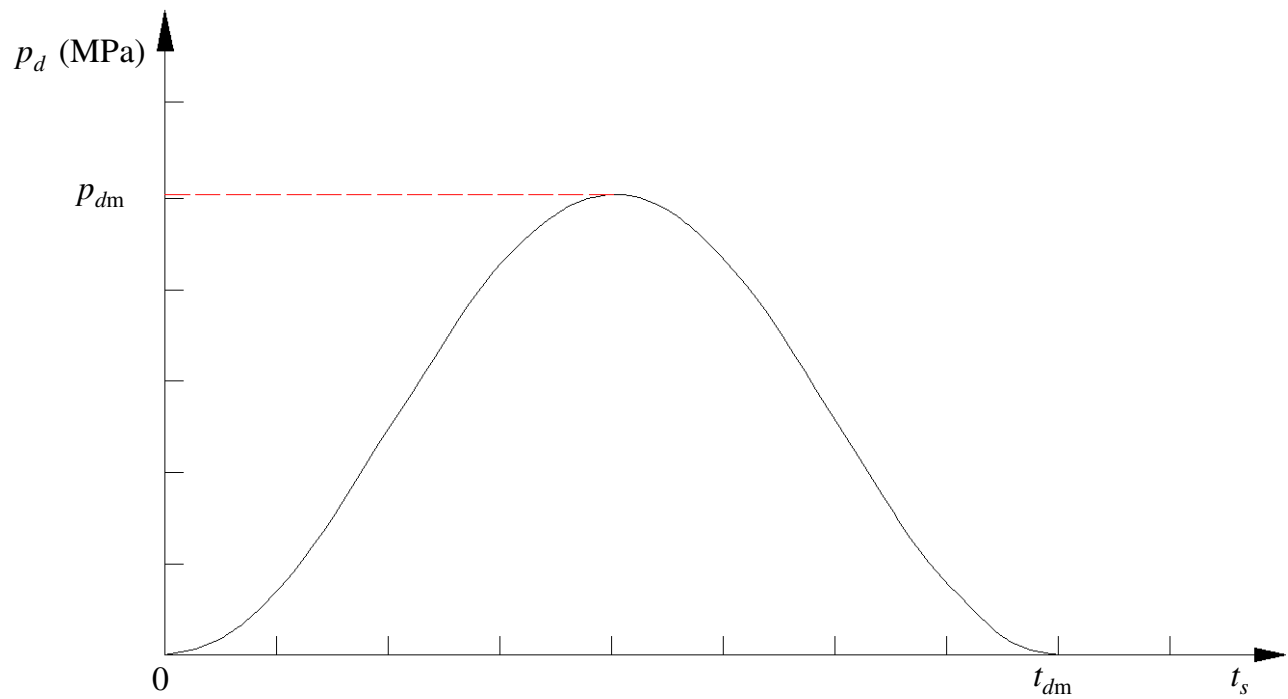

Fig. 5.The waveform of dynamic stress $p_{d}(t)$ with amplitude of $p_{d m}$ and duration of $t_{d m}$.

Table 2 Relationship between mine tremor energy and peak dynamic load

\begin{tabular}{c|c|c|c|c|c}
\hline NO. & Energy/J & $\begin{array}{c}\text { Wave velocity } \\
/(\mathrm{m} / \mathrm{s})\end{array}$ & $\begin{array}{c}\text { Density } \\
/\left(\mathrm{kg} / \mathrm{m}^{3}\right)\end{array}$ & PPV/(m/s) & $\begin{array}{c}\text { Peak dynamic load } \\
/ \mathrm{MPa}\end{array}$ \\
\hline 1 & $10^{3} \sim 10^{4}$ & 4500 & 2500 & 1.00 & 10 \\
2 & $10^{4} \sim 10^{5}$ & 4500 & 2500 & 2.90 & 30 \\
3 & $10^{5} \sim 10^{6}$ & 4500 & 2500 & 5.60 & 60 \\
4 & $10^{6} \sim 10^{7}$ & 4500 & 2500 & 9.40 & 100 \\
\hline
\end{tabular}

\subsection{Calibration of local damping coefficient in the dynamic analysis}

According to the manual for FLAC ${ }^{3 \mathrm{D}}$, there were two aspects that the user should consider for a dynamic analysis: (1) boundary conditions; and (2) mechanical damping. Here, the quiet boundary, developed by Lysmer and Kuhlemeyer[23], was chosen to reduce the reflection of propagating waves. The model is almost entirely effective at absorbing body waves approaching the boundary at angles of incidence greater than $30^{\circ}$ [22]. Damping is due, in part, to energy loss as a result of internal friction in the intact material or slippage along interfaces. Regarding the attenuation of elastic waves, local damping was considered in the dynamic analysis. In the numerical modelling of FLAC ${ }^{3 \mathrm{D}}$, the local damping coefficient $\alpha_{L}$ can be expressed as:

$$
\alpha_{L}=\pi D
$$

where $D$ is the critical damping coefficient.

The local dampingcoefficient canbecalibratedinthe numerical modelwith respecttocalculatedandmeasuredPPVs[24-25]. To determine the local damping parameters through this numerical analysis, a three-dimension model, including coal, roof and floor, was developed for the calculation. The modelhad

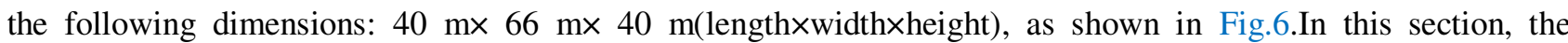
numerical model was run five times under conditions commensurate with different critical damping coefficients, i.e., the critical damping coefficient was set to $1 \%, 2 \%, 3 \%, 4 \%$, and 5\%, respectively. Afterwards, the PPVs at 
these monitoring points were recorded, and the points A and B are set $2 \mathrm{~m}$ and $12 \mathrm{~m}$ from the numerical model's centre, respectively. Based on the theoretical and numerical PPVs, the damping coefficient can be obtained and the calculated results are depicted in Fig.6. It can be seen that, with the increase of the critical damping coefficient, the PPV at point A increases: the resulting polynomial fit can be expressed as follows:

$$
y=-0.0036 x^{2}-0.5316 x+13.316
$$

While the ratio of PPV at point A to that at point $\mathrm{B}$ decreases,and the resulting polynomial fit can be expressed as follows:

$$
y=0.028 x^{2}+0.1355 x+2.5296
$$

It can be seen from Fig. 7 that the ratio of the PPV at point A to that at point B was 3.694: substituting $y=3.694$ into Eq. (13) gives $x=4.468$, which means that the critical damping coefficient in this dynamic analysis is $4.468 \%$.

To verify the calibrated damping coefficient, an additional run was performed, with the PPV and error valuesat different distances depicted in Fig. 8. It can be seen that the PPVs recorded $2 \mathrm{~m}$ and $12 \mathrm{~m}$ from the center of the equivalent cavity agree well with those calculated form theoretical calculation, the error can be limited to less than $12.7 \%$. The calibrated model thus represents real effects on the coal and rock mass, and the damping coefficient and modelling scheme are adopted in the following simulations.
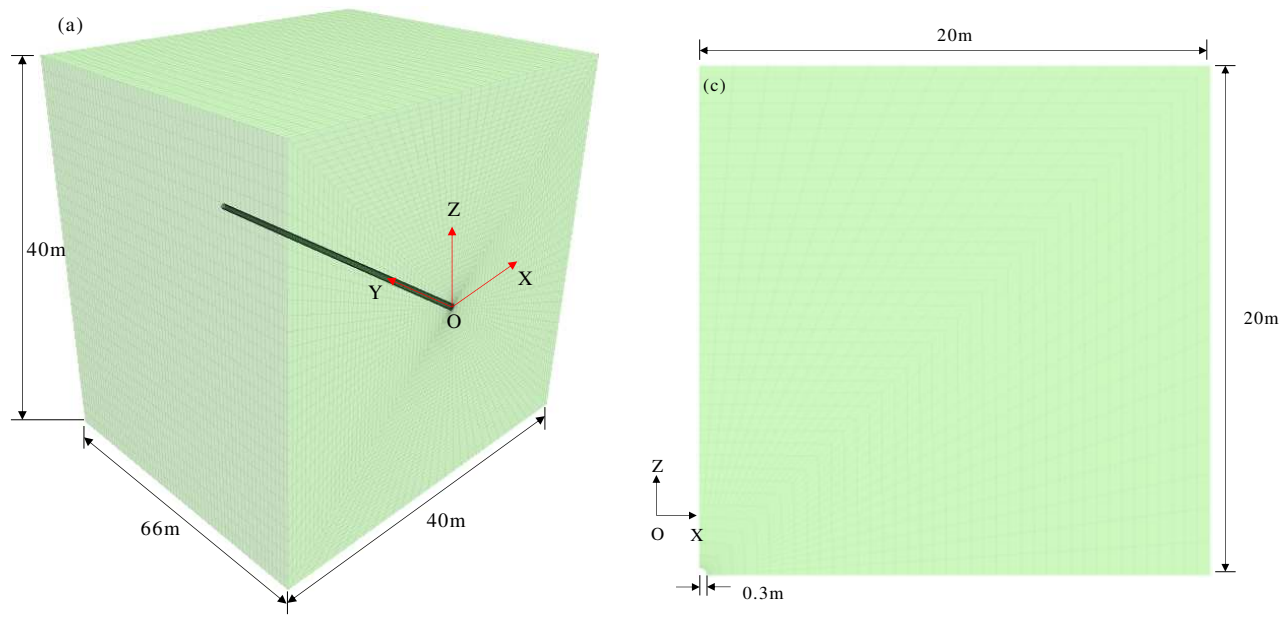


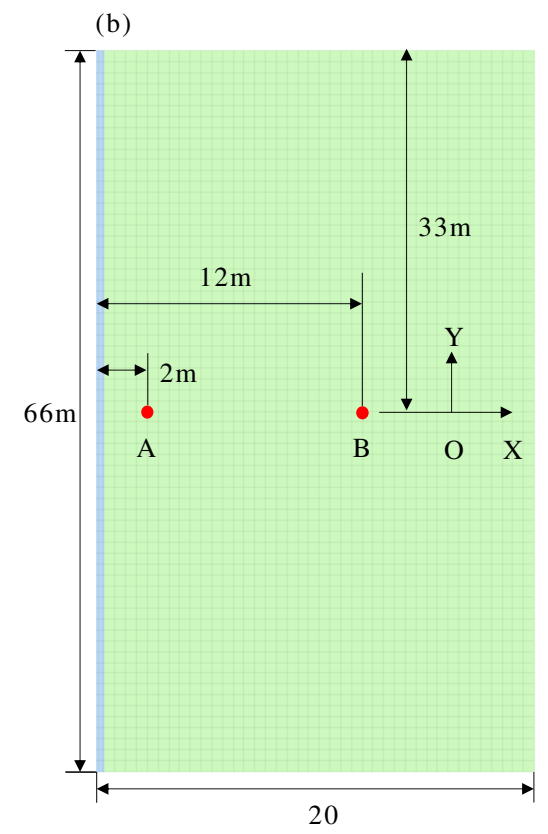

Fig. 6 Numerical simulation for dynamic analysis of local damping. (a) Numerical model geometry. (b) Sectional panel of the calibrated model $(z=0)$. (c) Sectional panel of the calibrated model $(y=0)$

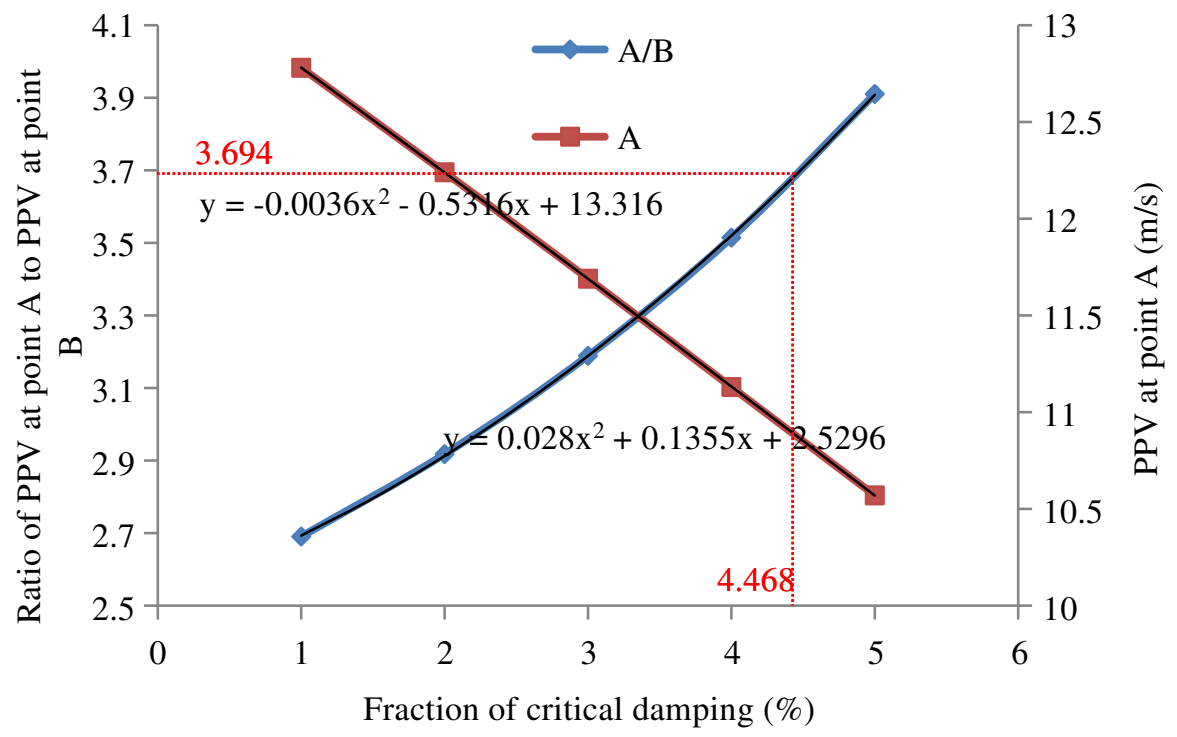

Fig.7 Graphs for calibration with respect to dynamic stress and local damping coefficient 


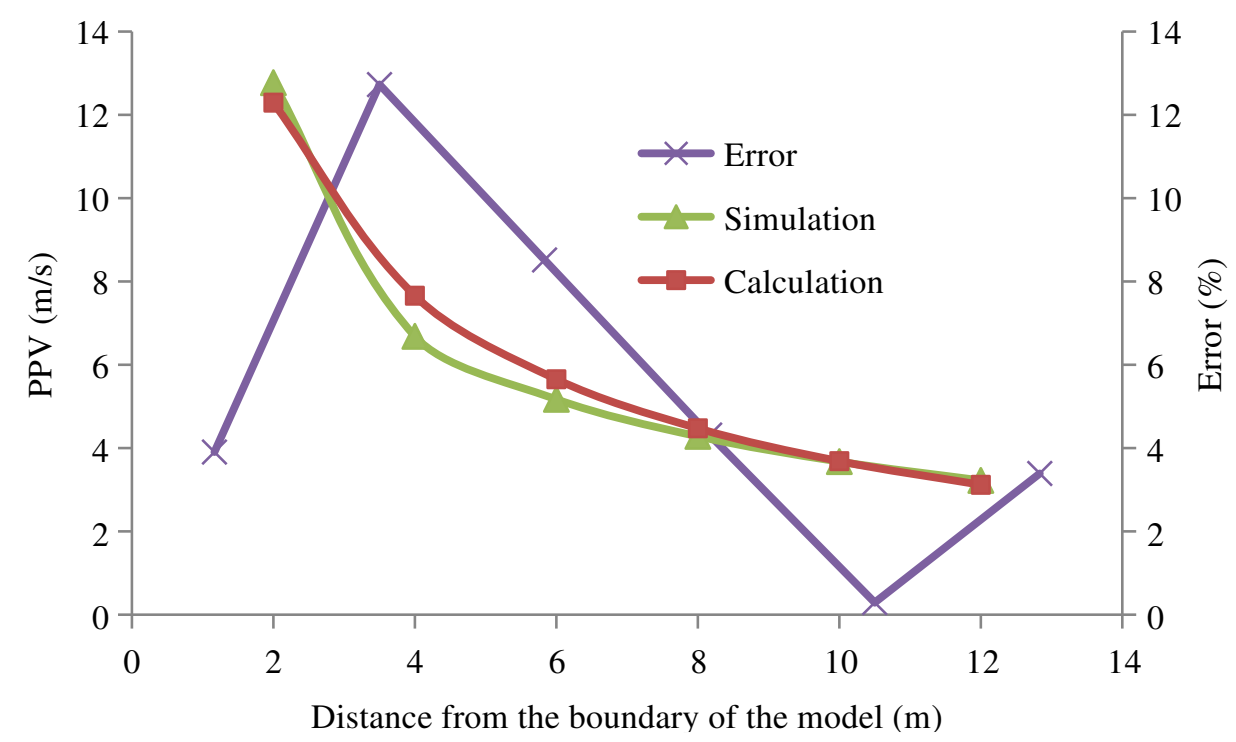

Fig.8 Error analysis of PPV with increasing distance

\section{Numericalsimulation results and discussions}

\subsection{Comparison of experiment and numerical simulation}

The comparison of the stress-strain curves obtained by the numerical model and that of the laboratory test is shown in Fig. 4.Readers may find that the proposed numerical curve is not well fitted to the experimental curves of stress-strain, especially in the initial stage. It is because that the numerical calculation can't effectively simulate the initial stage of the curve, a large number of experiments show that this stage is called the crack compression stage. The numerical simulation doesn't take into account thenaturally existing cracksand the mechanical properties of the model. Therefore, eliminating the influence of the initial stage, i.e., translating the simulation curve, the "numerical-correction" curve can be obtained (red dotted line in Fig. 9).Then, it can be seen that the numerical simulation stress-strain curve of the model matches the laboratory test data very well.

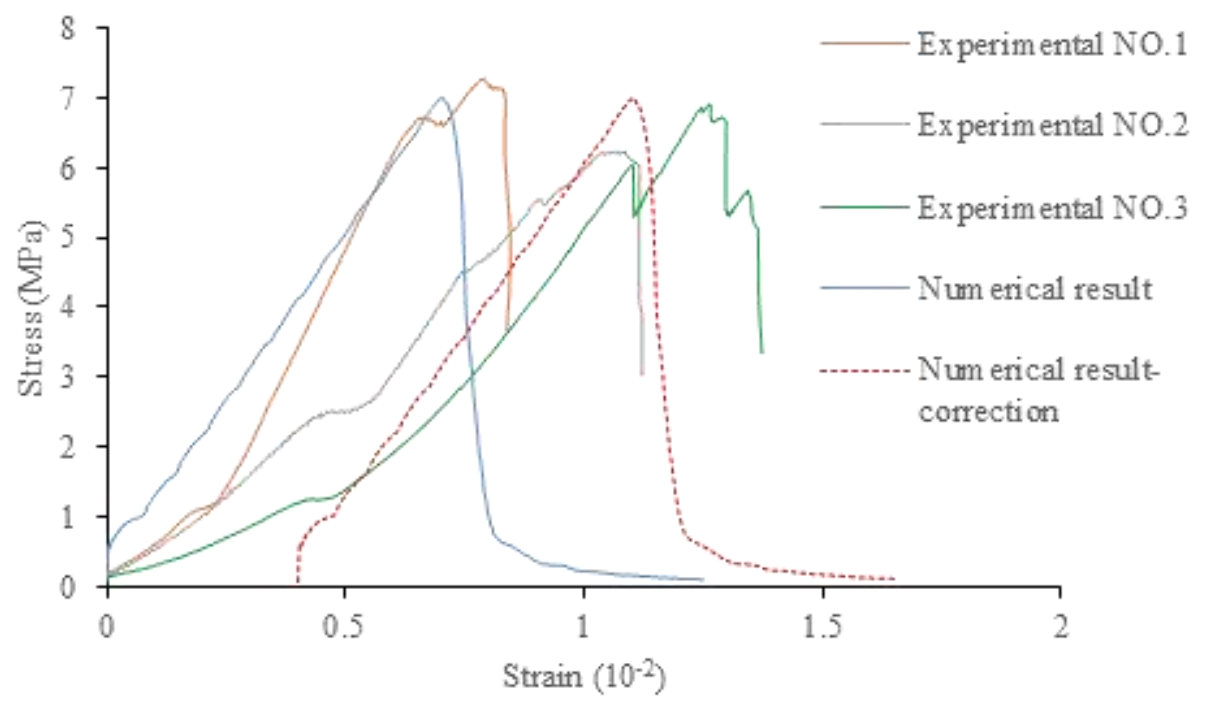

Fig. 9.Stress vs strain experimental and numerical curves for coal specimens.

\subsection{Dynamic behavior}


The dynamic module was used to investigate the response features of the coal pillar under dynamic disturbance. In this section, 6 monitoring points were set up in the interior of the model $(x=0.025 \mathrm{~m}, \mathrm{y}=0.025 \mathrm{~m}$, $\mathrm{z}=0-0.1 \mathrm{~m})$, as shown in Fig. 10.

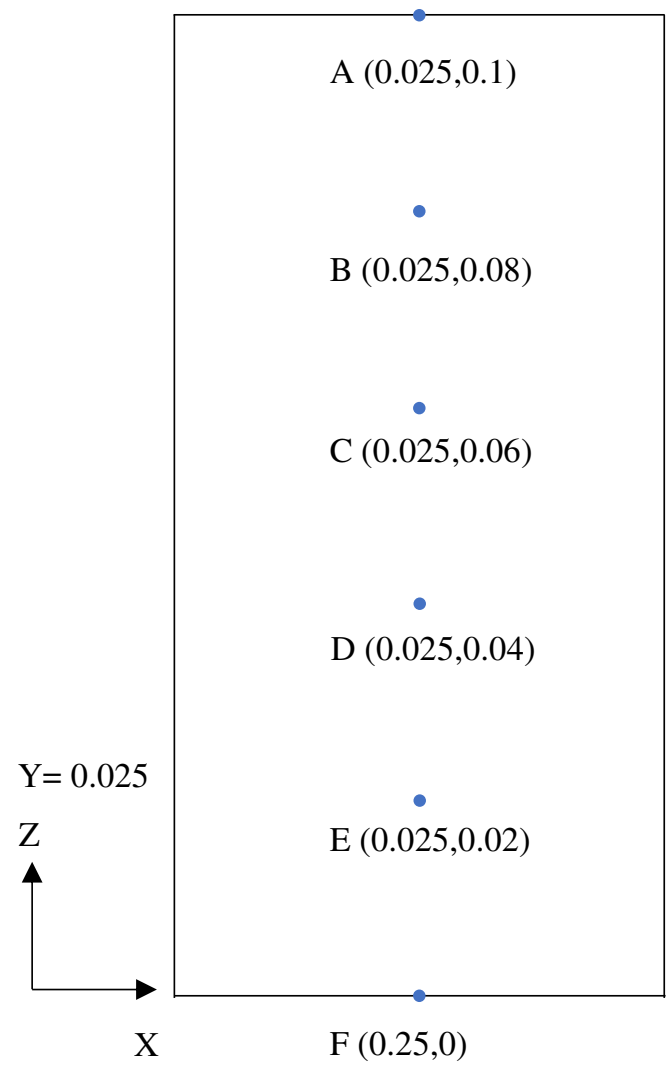

Fig. 10.Cross-section of the model, in which 6 typical points where the stresses will be retrieved.

\subsubsection{Effect of load percentage}

If the dynamic disturbance intensity is constant (10MPa), the evolution of the incident and transmitted wave stress with different LD is shown in Fig. 11.In the entire process (take Fig. 11.(d) as an example), the stress wave evolution for various LD follows a similar rule and the time history curve of stress wave variation can be divided into three stages: namely, static preload stage, dynamic disturbance stage, stabilized stage.

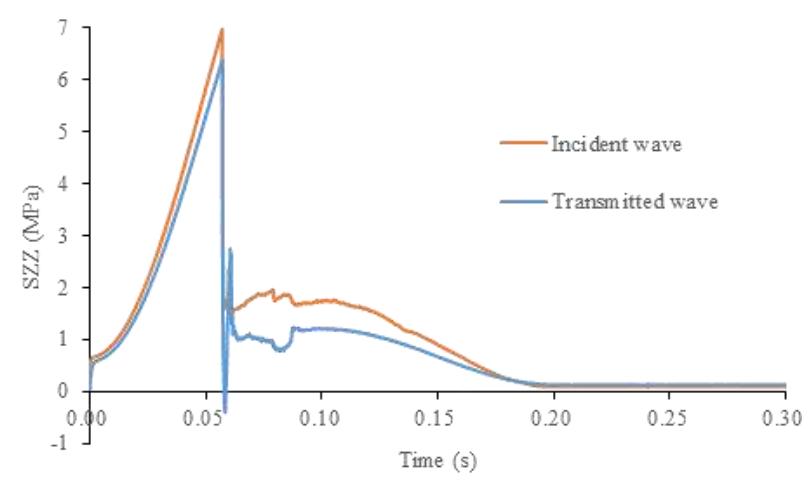

(a)

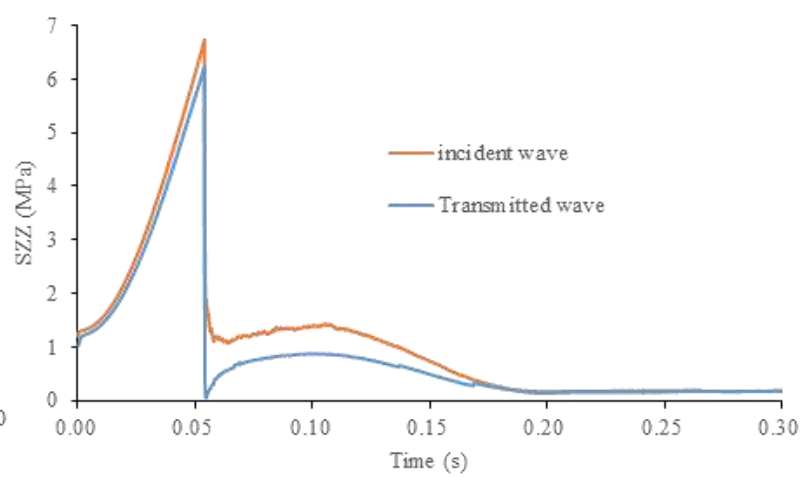

(b) 


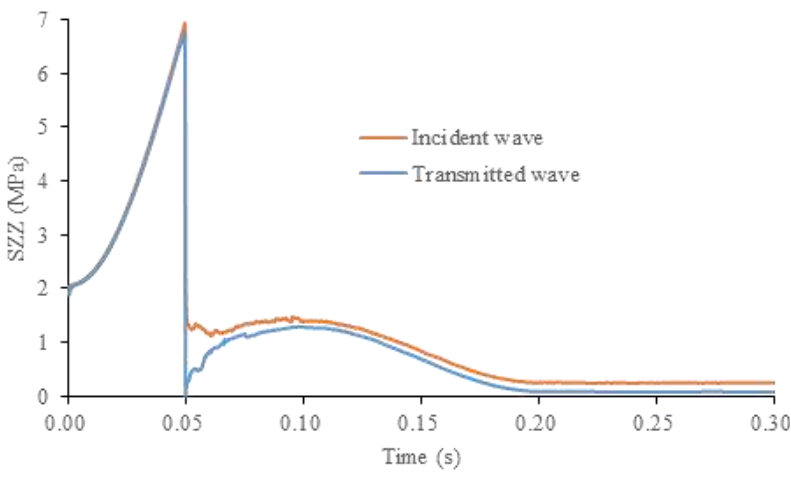

(c)

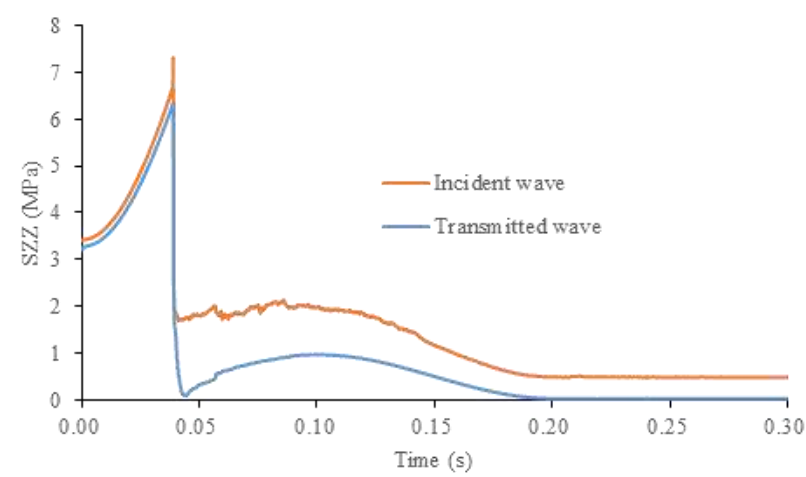

(e)

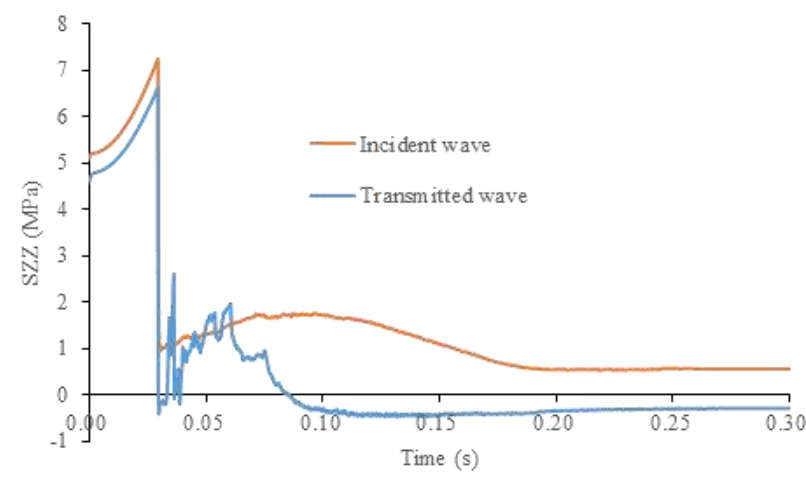

(g)

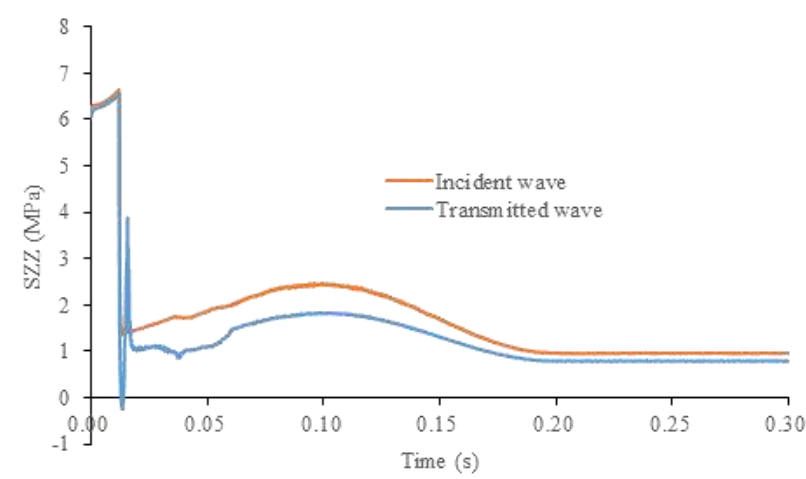

(i)

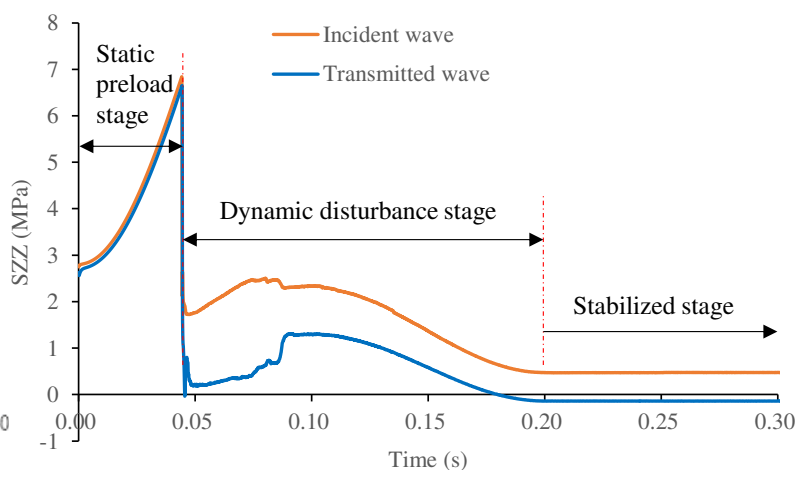

(d)

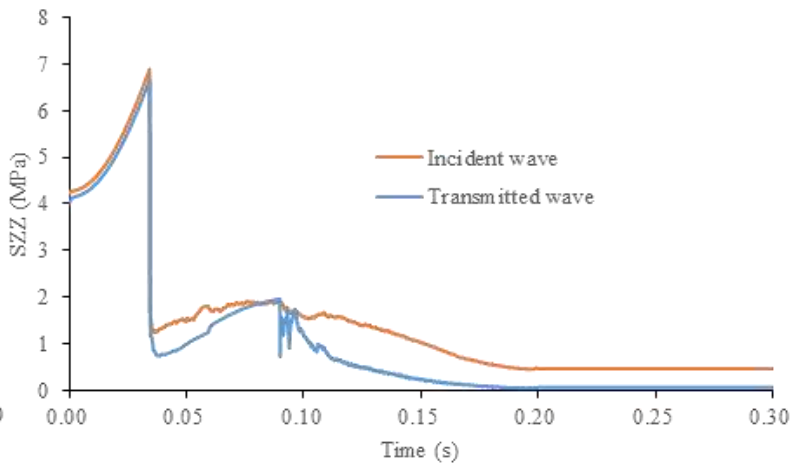

(f)

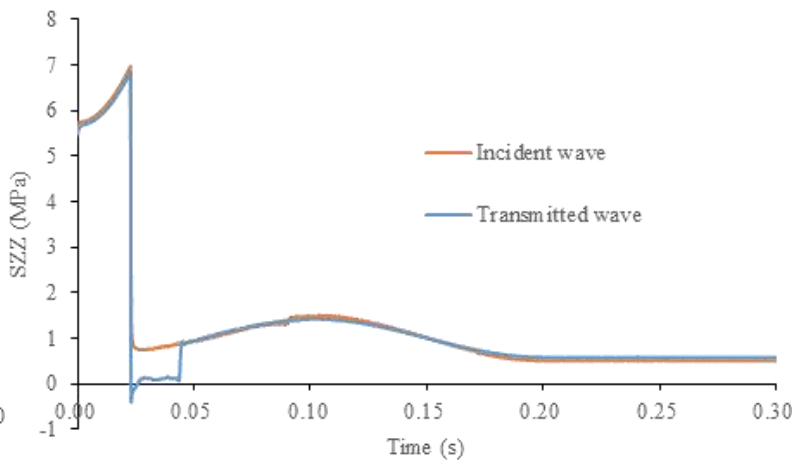

(h)

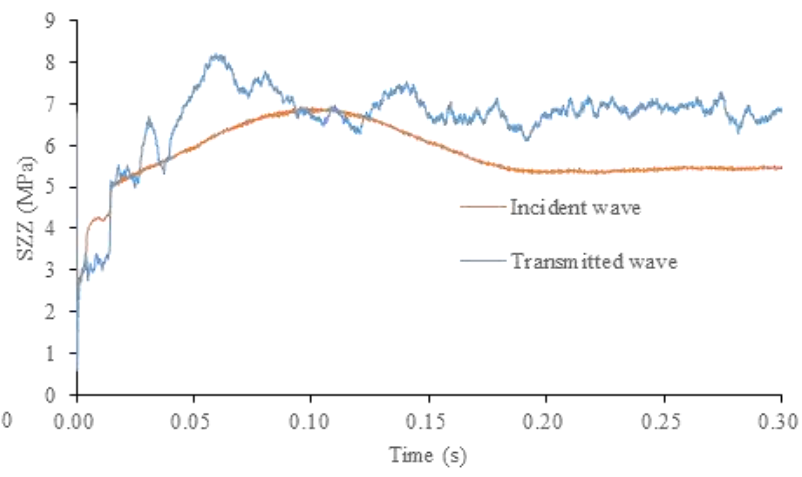

(j)

Fig. 11.Waveform of the incident and transmission for the model with different LD. From Fig. 11.(a) toFig. 11.(j), the $\mathrm{LD}$ is from $10 \%$ to $100 \%$, respectively.

(1) Static preload stage:at the beginning, the stresses on the two ends of the model are different until it 
reaches the uniaxial compression strength (about $7 \mathrm{MPa}$ ). The reason is that before the dynamic disturbance, the simulation model is subject to the static preload through the boundary, which is already compressed and thus the stress gauge interior the model measured the preload.

(2) Dynamic disturbance stage: this stage lasts for $\sim 0.2 \mathrm{~s}$, which is the main dynamic disturbance period.The wave stress reached a peak value at $0.1 \mathrm{~s}$ at this stage.

(3) Stabilized stage: when the calculation time exceeds $0.2 \mathrm{~s}$, the wave stress is maintained at a low level and the models reach equilibrium.

Another interesting phenomenon found in from Fig. 11.is that the duration of the first stage gets shorter and shorter. With an increase in load percentage, the static preload in the coal increases.Consequently,theduration of the static preload stage decreases.

The relationship betweenwave attenuation andLD is shown inFig. 12. Statistic show that for models with different $\mathrm{LD}$, the curves present their periodic changes. When $\mathrm{LD} \leqslant 30 \%$,for an increase in $\mathrm{LD}$, the attenuation coefficient decreases almost linearly. The reason for this phenomenon is that the cracks in the coal models close, thus the wave attenuation decreases sharply. When $\mathrm{LD}=40 \% \sim 70 \%$, the attenuation coefficient is almost constant (about 50\%). When $\mathrm{LD} \geqslant 80 \%$, compression-induced cracks form again and parts of micro-units start to damage. Therefore, the increase in LD makes the concentration more obvious and leads to further attenuation.

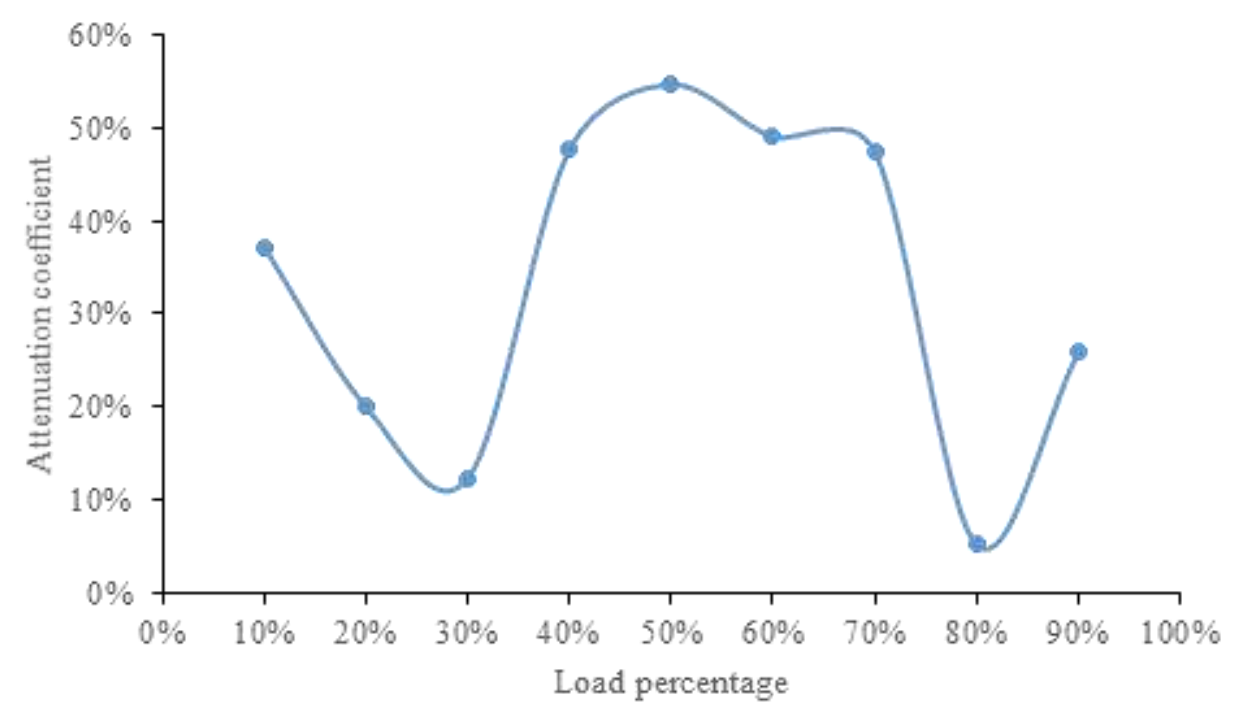

Fig. 12.Attenuation coefficient versus time curve for different load percentage.

The stress wave evolution recorded at the monitoring points for a constant LD (40\%) is presented in Fig. 8.In general, the attenuation of stress wave in coal and rock mass shows a power relation with the propagation distance, i.e., the longer the distance is, themore evident the attenuation isat a certain distance [26]. However, due to various $\mathrm{LD}$, the wave propagation is no longer uniform. By comparing the recorded data, we can see thatthe recordedpeak vertical stressof monitoring points $\mathrm{C}$ and $\mathrm{D}$ are larger than the ones of points $\mathrm{B}$ and $\mathrm{E}$. This means dynamic 
disturbance is obvious as the monitoring points gets close to the two ends of the model, where the load applied to the micro-unit is much higher and leads to varying degrees of damage. The results indicate that the failure zone interior the coal can be predicted by the wave propagation.

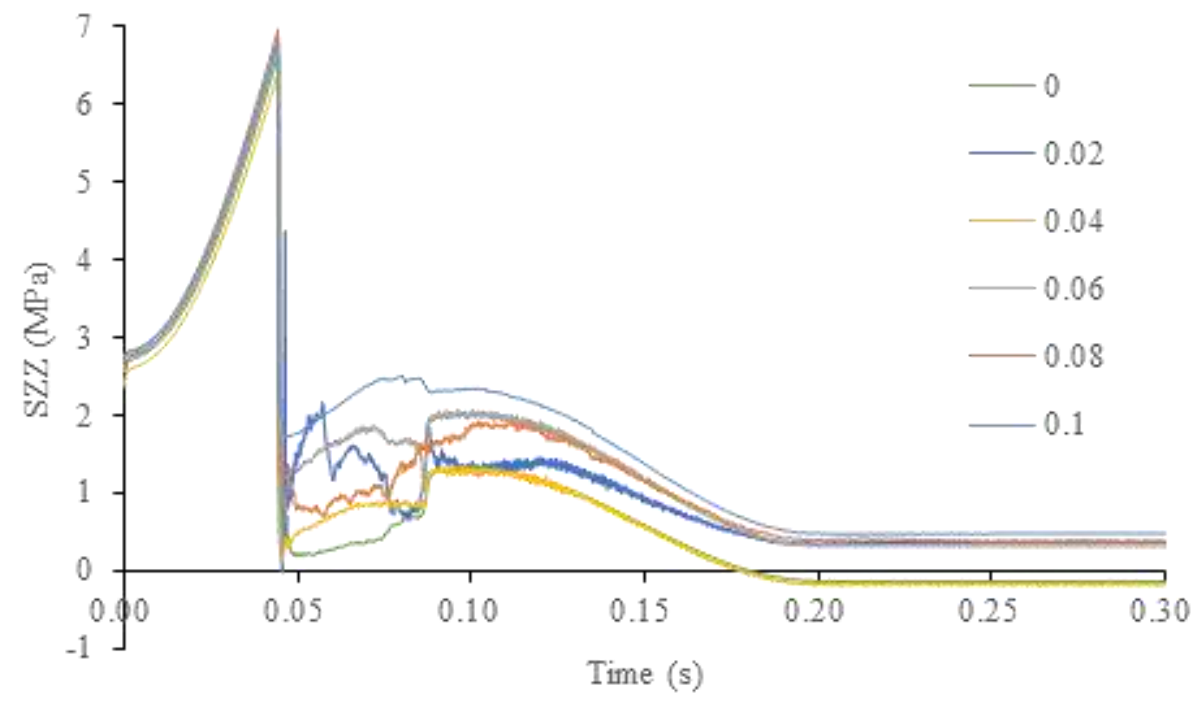

Fig. 13.Curves of vertical stress varying with time of monitoring points $(\mathrm{LD}=40 \%)$.

\subsubsection{Effect of dynamic disturbance intensity}

The change in vertical stress for different dynamic disturbance intensity is shown in Fig. 14. It can be seen that the dynamic disturbance intensity has a large influence on the evolution of stress. At the specific value of load percentage (40\%), with the increase of the amplitude of dynamic disturbance intensity, the recorded stresses varies greatly. To better understand these relationships, the detailed data are plotted in Fig. 15.With increasing dynamic disturbance intensity,the peak incident wave stress increases from 2.33 MPa to 4.02 MPa and the peak transmitted wave stress increases from 1.28MPa to $3.81 \mathrm{MPa}$. However, the attenuation of the incident wave stress varies slightly, which trends to be zero when $\mathrm{p}_{\mathrm{dm}} \geqslant 30 \mathrm{MPa}$.

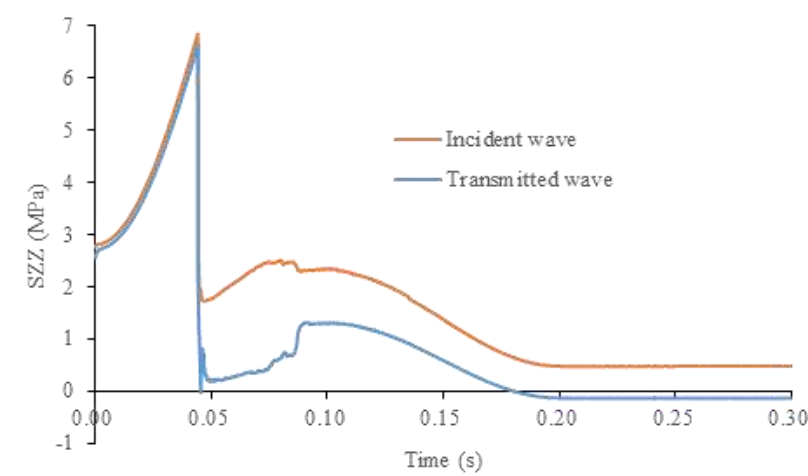

(a)

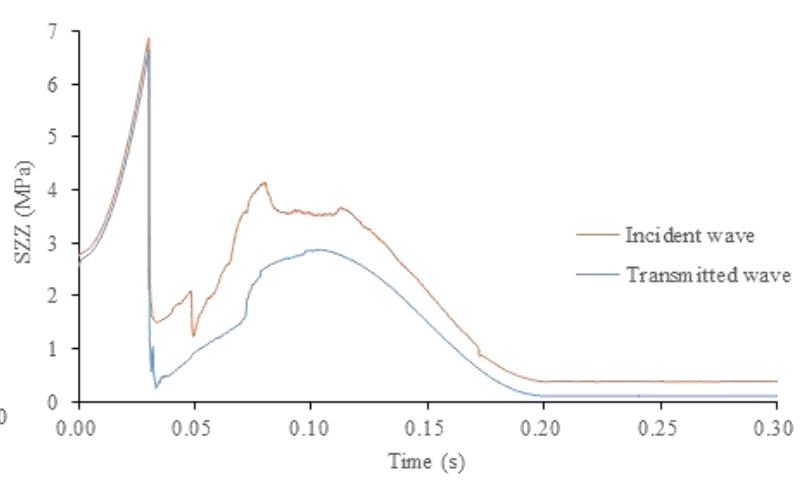

(b) 


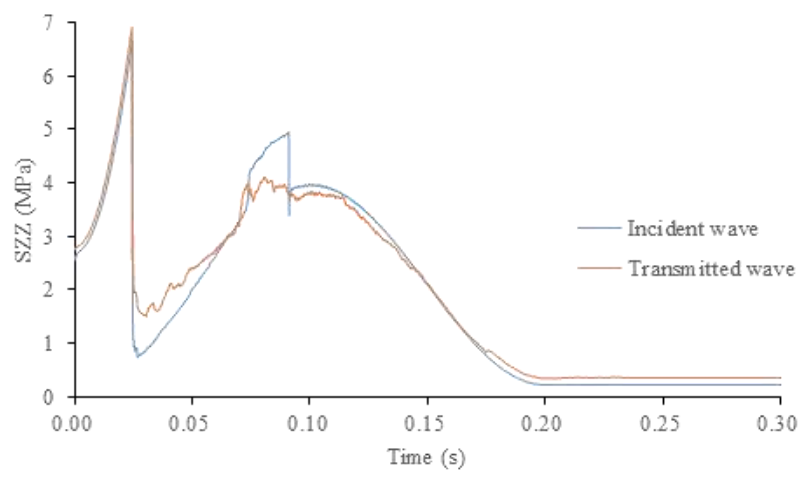

(c)

Fig. 14. Vertical stress versus time curves for different dynamic disturbance intensity(load percentage $=0.4$ ): (a) 10 MPa; (b) $20 \mathrm{MPa}$; (c) $30 \mathrm{MPa}$.

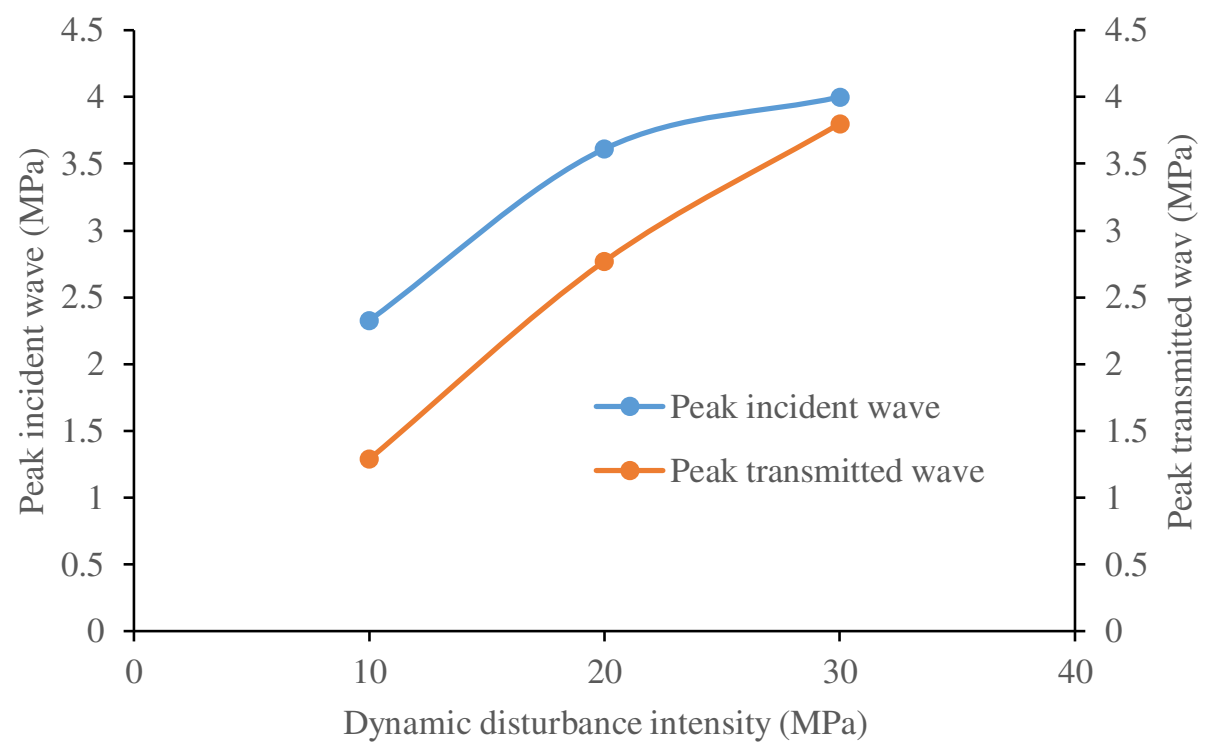

Fig. 15.Effect of dynamic disturbance intensity on the peak value of incident and transmitted wave stress.

\section{Conclusions}

The focus of this study is to investigate dynamic behavior of the coal pillar under different load percentage. Based on laboratory coal strength data, a statistical constitutive damage model for coal under uniaxial compression was established. Numerical models considering experimental result were generated by FLAC ${ }^{3 \mathrm{D}}$ software. The following main conclusions can be drawn:

(1) For the entire process, the stress wave evolution for various load percentage follows a similar rule and the time history curve of stress wave variation can be divided into three stages: namely, static preload, dynamic disturbance and stabilized stage.

(2) When LD $=0 \sim 30 \%$, the attenuation coefficient decreases almost linearly and sharply. While $\mathrm{LD}=40 \% \sim 70 \%$, the attenuation coefficient is almost constant. If $\mathrm{LD} \geqslant 80 \%$, compression-induced cracks form again and parts of micro-units start to damage, which leads to further attenuation.

(3) With increasing dynamic disturbance intensity, the peak incident and transmitted wave stress increase 
whist the attenuation decrease.

\section{Conflict of Interests}

The authors declare that there is no conflict of interests regarding the publication of this paper.

\section{Acknowledgments}

This work was supported and financed by Natural Science Foundation of Shaanxi Province (Grant No.: 2020JM-519), China Postdoctoral Science Foundation(Grant no.2018M643692), the National Natural Science Foundation of China (Grant nos. 51904235 and 51974231), Natural Science Foundation of Shaanxi Province (Grant No. 2019JQ-487).

\section{Author Contributions}

Dong, G. and Zhu, G. conceived and designed the experiments; Liu, H. performed the experiments and numerical simulation; Dong, G. and Zhu, G. analysed the data; Dong, G. and Zhu, G. wrote the paper.

\section{Reference:}

[1] DOU Lin-ming, MU Zong-long, LI Zhen-lei, et al. Research progress of monitoring, forecasting, and prevention of rockburst in underground coal mining in China [J]. International Journal of Coal Science and Technology, 2014, 1(3): 278-288.

[2] Zhang C, Canbulat I, Hebblewhite B, et al. Assessing coal burst phenomena in mining and insights into directions for future research[J]. International Journal of Coal Geology, 2017, 179:28-44.

[3] S.-Y. Wang, K.-C. Lam, S.-K. Au, et al. Analytical and numerical Study on the pillar rockbursts mechanism[J].Rock Mechanics and Rock Engineering, 2006, 39(5): 445-467.

[4] G.-A. Zhu, L.-M. Dou, A.-Y. Cao, et al. Assessment and analysis of strata movement with special reference torock burst mechanism in island longwall panel[J].Journal ofCentral South University, 2017, 24(12):2951-2960.

[5] WANG Bo, JIANG Fu-xing, ZHU Si-tao, et al. Mechanism and prevention of rock burst induced by segment pillars in the deep mining areas of Shaanxi-Inner Mongolia adjacent regions [J]. Journal of Mining \& Safety Engineering, 2020, 37(3):505-513. (in Chinese)

[6] WANGTao, YOUShuang, PEI Feng, et al. Instability mechanism and control technology of coal pillar bumps under hard roof[J]. Journal of Mining \& Safety Engineering, 2017, 34(1): 54-59, 66. (in Chinese)

[7] M.D.-G. Salamon. Stability, instability and design of pillar workings[J].International Journal of Rock Mechanics \& Mining Sciences, 1970, 7(6): 613-631.

[8] J.-M. Galvin, “Considerations associated with the application of the UNSW and other pillar design formulae," In: Proceedings of the 41st US symposium on rock mechanics, Golden, Colorado, pp. 1129-37, 2006.

[9] Yuan L, Jiang Y D, He X Q, et al. Research progress of precise riskaccurate identification and monitoring early warning on typical dynamic disasters in coal mine[J]. Journal of China Coal Society, 2018, 43(2): 306-318. (in Chinese)

[10] Robert B, Kurt D, Garry M. An Approach to model the strength of coal pillars[J].International Journal of Rock Mechanics \& Mining Sciences, 2016, 89: 165-175.

[11] Wang G F, Gong S Y, Li Z L, et al. Evolution of stress concentration and energy release before rock bursts:two case studies from Xingan coal mine, Hegang, China [J].Rock Mechanics and Rock Engineering,2016, 49 (8): 3393-3401.

[12] Sankhaneel S, Gabriel W. Investigation of longwallheadgate stress distribution with an emphasis on pillar behavior[J]. International Journal of Rock Mechanics \& Mining Sciences, 2019, 121: 104-409.

[13] A Jaiswal, B Kshrivastva. Numerical simulation of coal pillar strength[J].International Journal of Rock Mechanics \& Mining Sciences, 2009, 46: 779-788. 
[14] H.-W. Wang, Y.-D. Jiang,Y.-X, etal. Numerical investigation of the dynamic mechanical state of a coal pillar during longwall mining panel extraction[J].Rock Mechanics and Rock Engineering, 2013, 46: 1211-1221.

[15] B.-A.Poulsen, B.Shen, D.-J.Williams, et al. Strength reduction on saturation of coal and coal measures rocks with implications for coal pillar strength[J].International Journal of Rock Mechanics \& Mining Sciences, 2014, 71: 41-52.

[16] Wang S L, Hao S P, Chen Y, et al. Numerical investigation of coal pillar failure under simultaneous static and dynamic loading[J]. International Journal of Rock Mechanics \& Mining Siences, 2016, 84:59-68.

[17] S.-C. Yuan, J.-P. Harrison. A review of the state of the art in modelling progressive mechanical breakdown and associated fluid flow in intact heterogeneous rocks[J].International Journal of Rock Mechanics \& Mining Sciences, 2006, 43(7): 1001-1022.

[18] Z.-X. Li.Damage mechanics and its application, Science Press, Beijing, 2002.

[19] W.-Y.Xu, L.-D. Wei. Study on statistical damage constitutive model of rock[J].Chinese Journal of Rock Mechanics and Engineering, 2002, 21(6): 787-791. (in Chinese)

[20] Zhen. Wu, Chen-juan. Zhang. Investigation of rock damage model and its mechanical behaviour[J].Chinese Journal of Rock Mechanics and Engineering, 1996, 15(1): 55-61. (in Chinese)

[21] Sheng-qi. Yang, Wei-ya. Xu, Li-de. De,et al. Statistical constitutive model for rock damage under uniaxial compression and its experimental study [J].Journal of Hohai University (Natural Sciences), 2004, 32(2):200-203. (in Chinese)

[22] Itasca Consulting Group Inc, FLAC3D Fast Lagrangian Analysis of Continua in 3 Dimensions User's Guide, Itasca ConsultingGroup Inc, Minneapolis, Minn, USA, 2012.

[23] Lysmer J, Kuhlemeyer R L. Finite dynamic model for infinite media [J]. J Eng Mech, 1969, 95(EM4): 859-877.

[24] Sainoki A, Mitri H S. Dynamic modeling of fault slip induced by stress waves due to stope production blasts[J]. Rock Mechanics and Rock Engineering, 2016, 49(1): 165-181.

[25] Zhu G A, Dou L M, Wang C B, et al. Numerical investigation of the evolution of overlying strata and distribution of static and dynamic loads in a deep island coal panel[J]. Arabian Journal of Geosciences, 2017, 10(24):549.

[26] B. Liu, C.-P. Lu, L.-M. Dou, et al. Simulation study on shock wave propagation character in coal and rock[J].Journal of China Coal Society, 2011, 36(S2): 247-253.(in Chinese) 
Figures

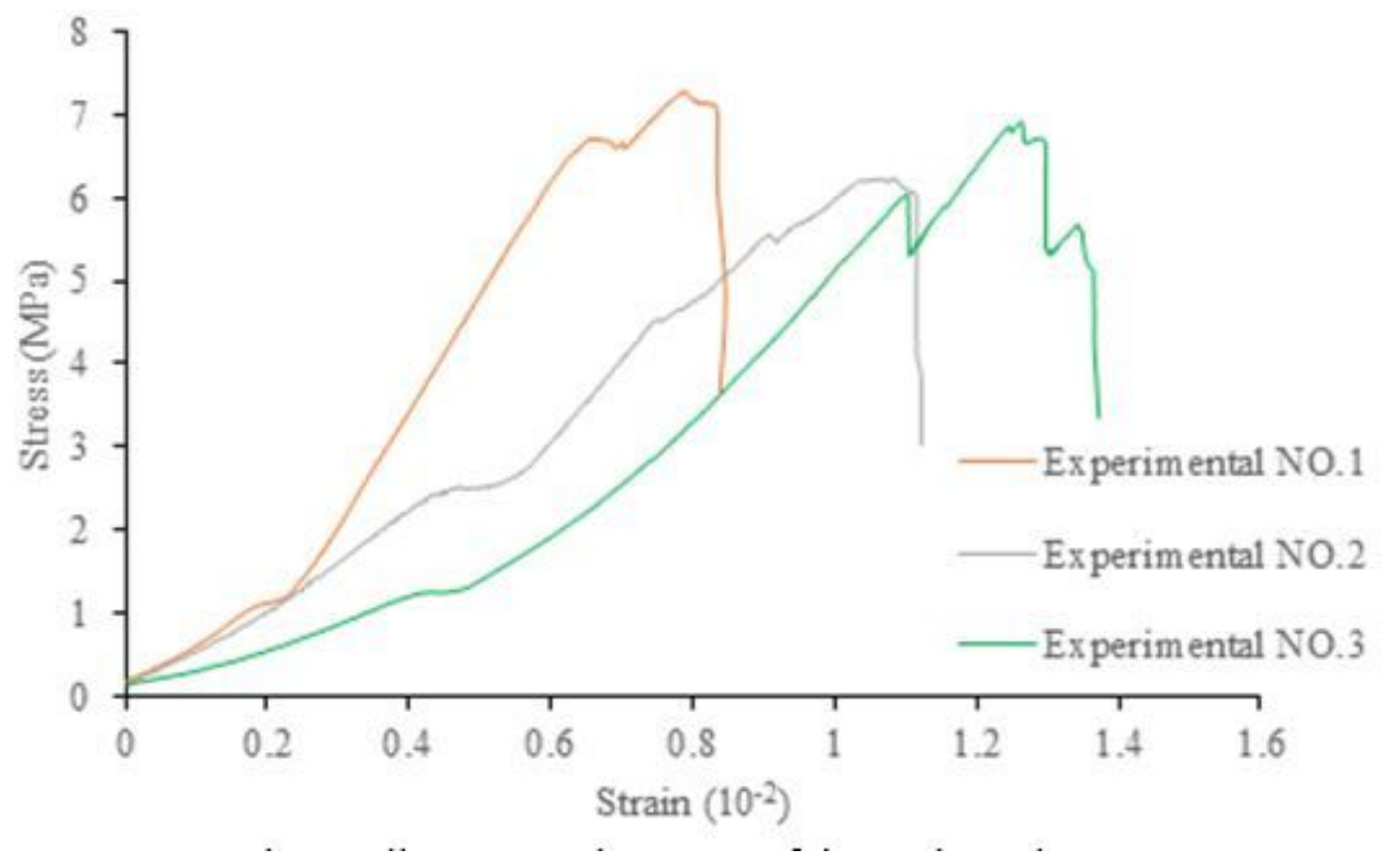

Figure 1

Full stress-strain curves of the coal specimens. 


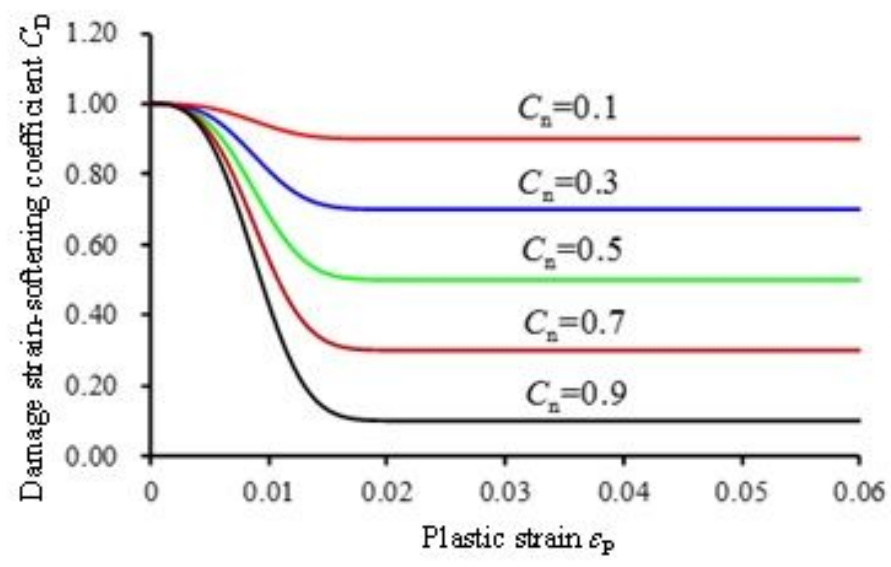

(a) $F=0.01, \quad m=3$

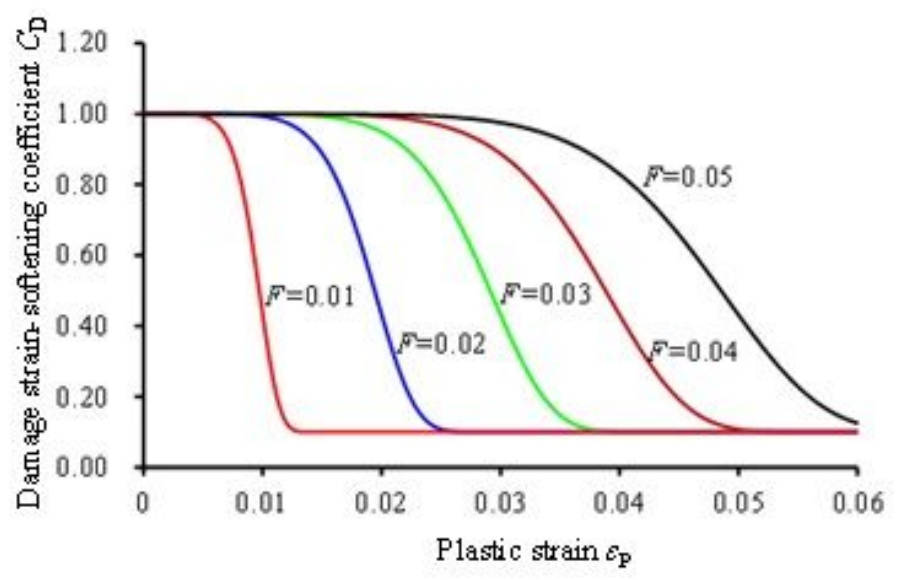

(c) $m=7, \quad C_{\mathrm{n}}=0.9$

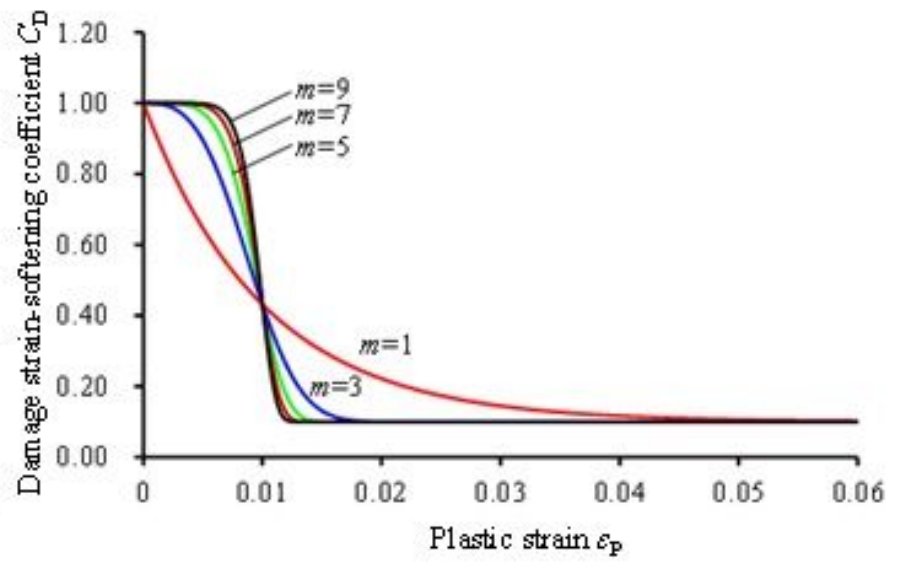

(b) $F=0.01, \quad C_{n}=0.9$

\section{Figure 2}

Variation of the damage strain-softening coefficient $C D$ with the parameters of $C n, m$, and $F$ changing 


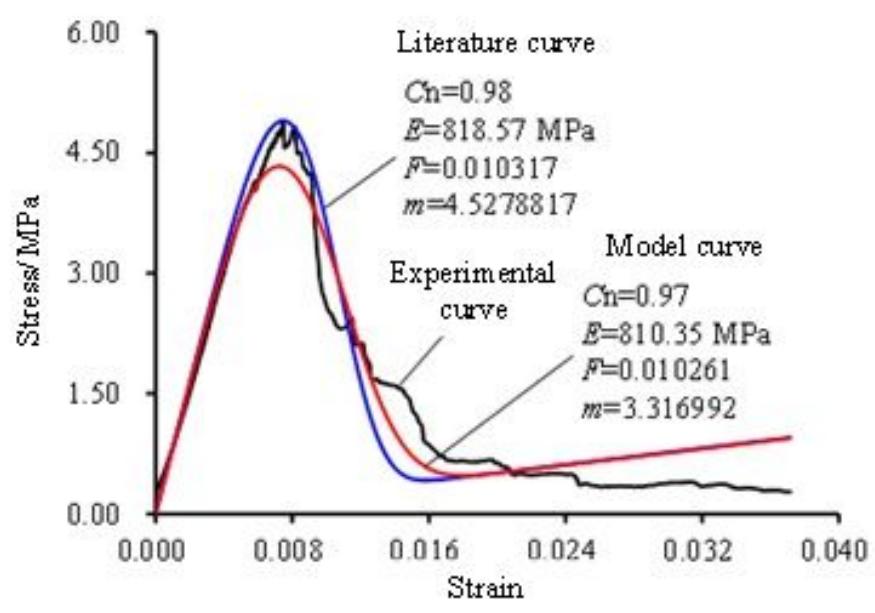

(a)coal sample 1

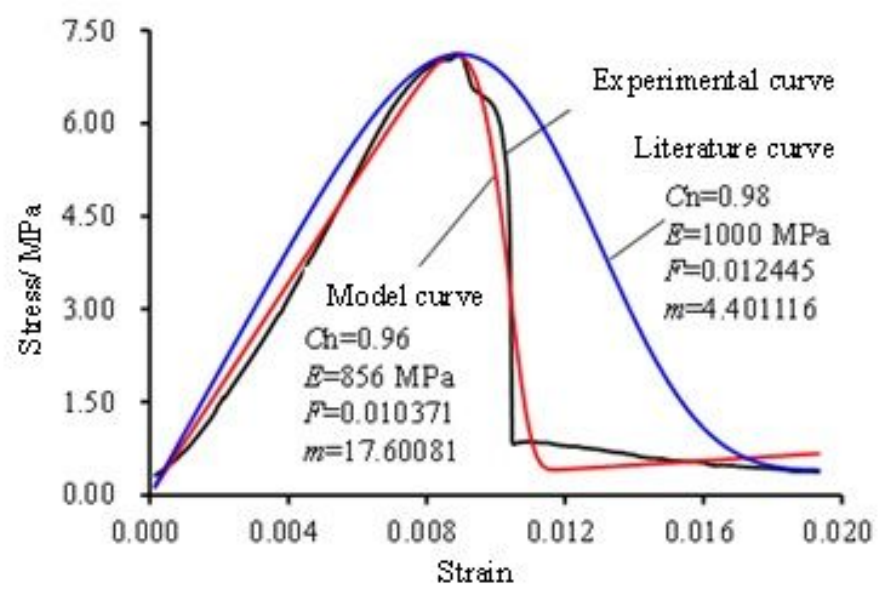

(c)coal sample 3

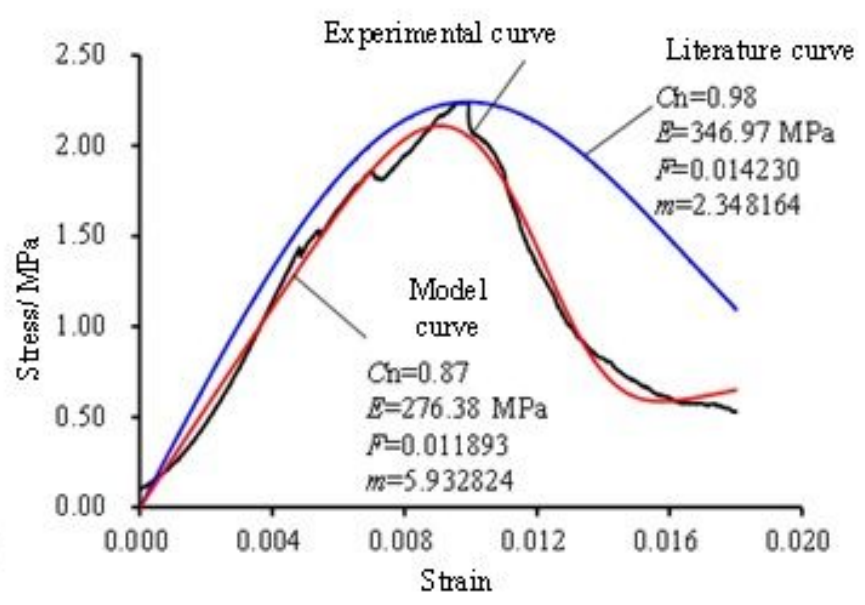

(b) coal sample 2

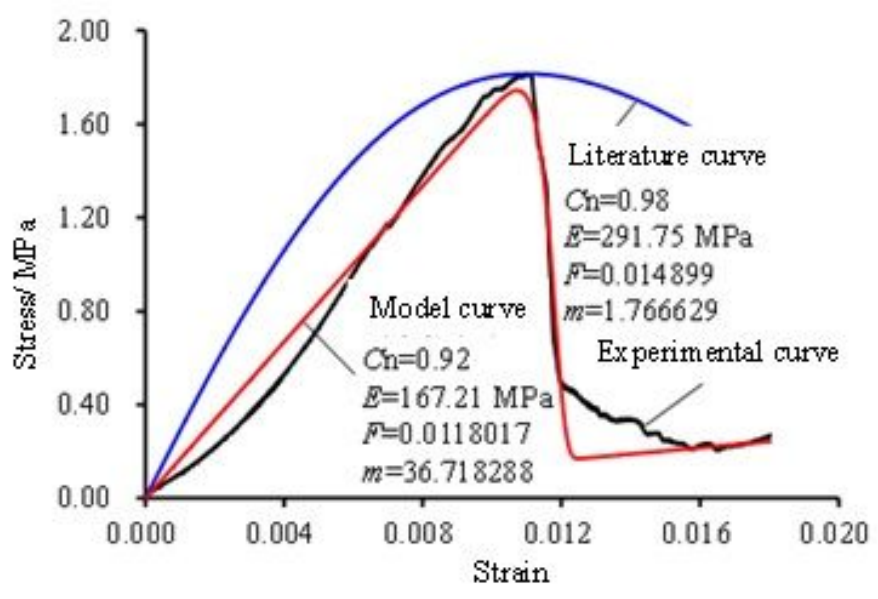

(d) coal sample 4

\section{Figure 3}

Comparison between experimental curves and theoretical curves 


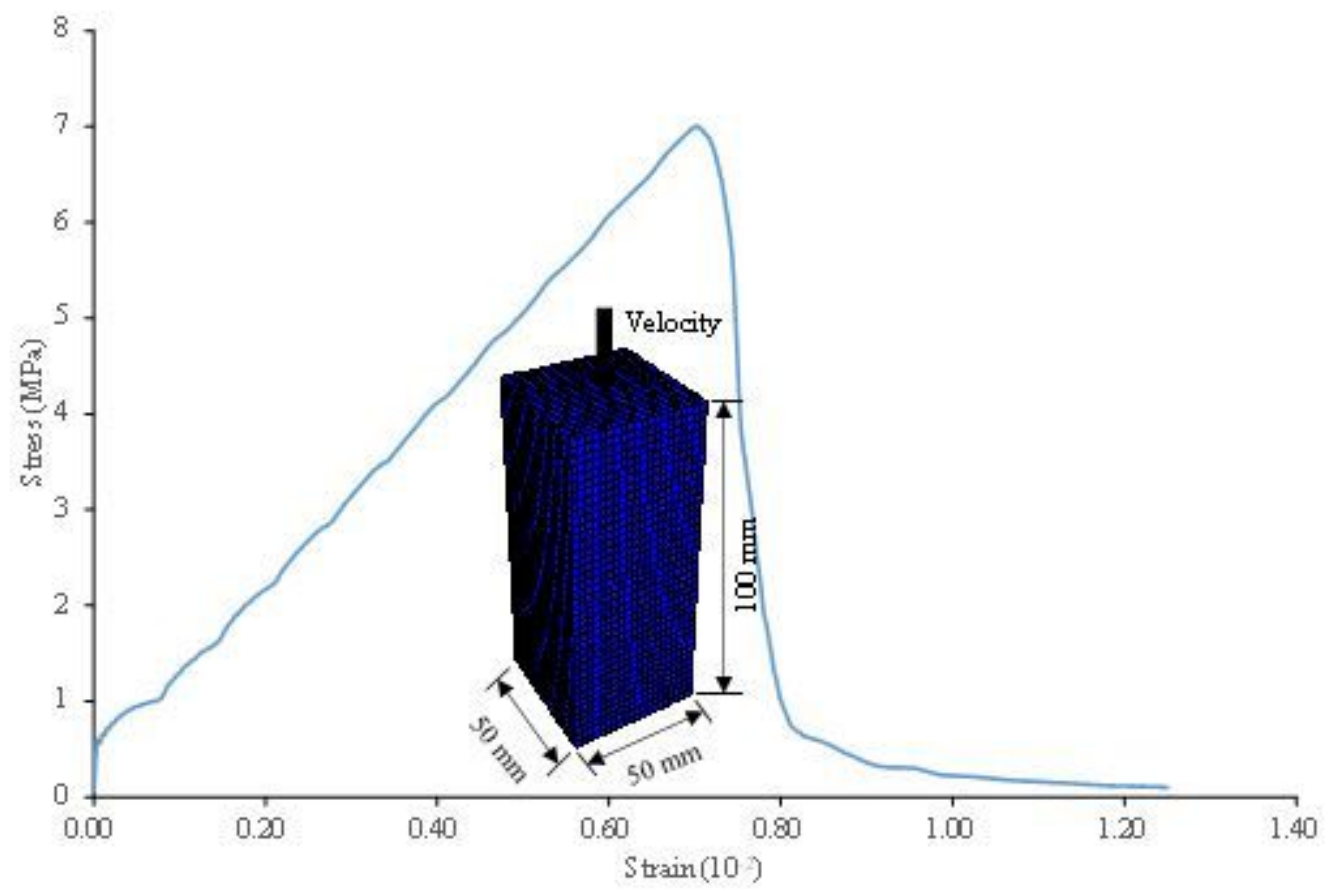

Figure 4

A sketch of FLAC3D mesh and the stress-strain curve of the numerical model.

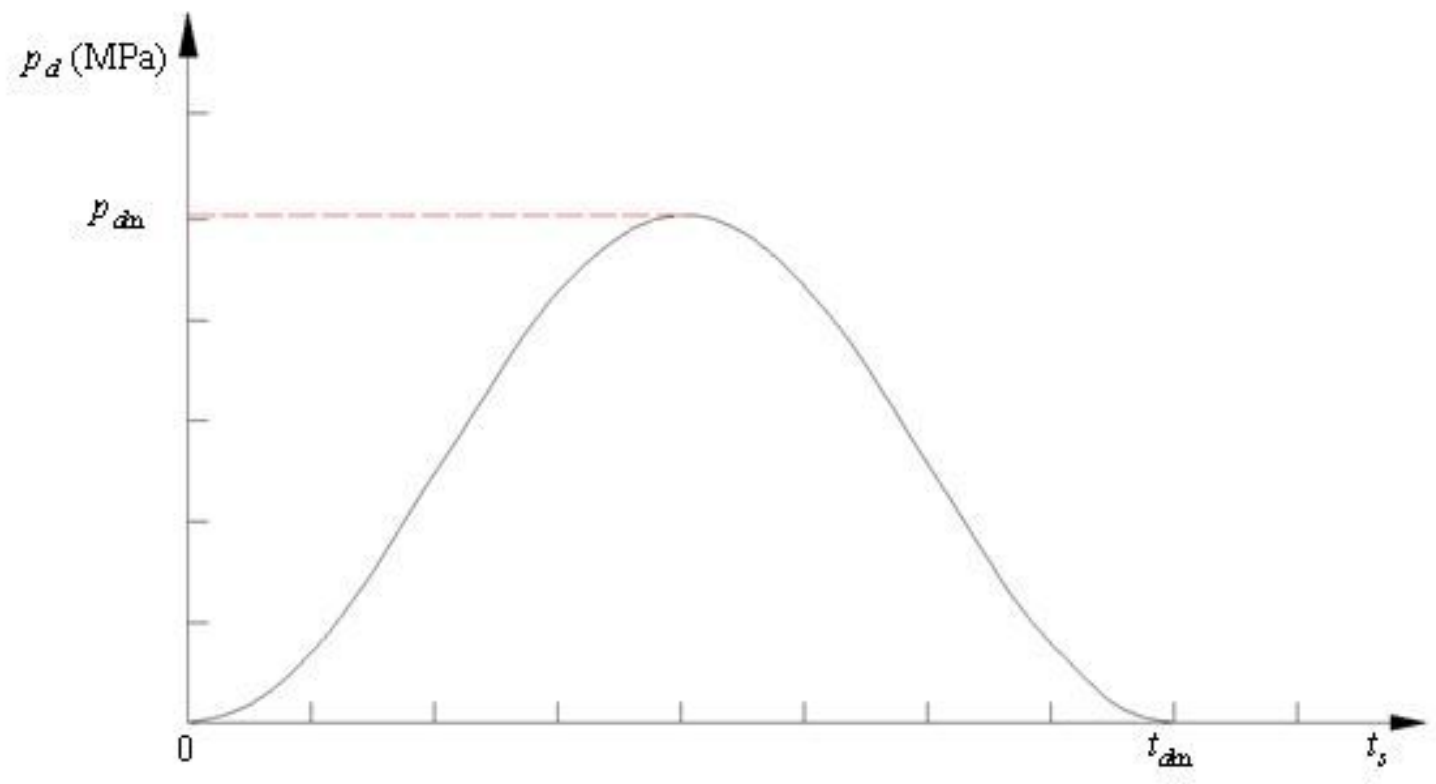

Figure 5

The waveform of dynamic stress $\mathrm{pd}(\mathrm{t})$ with amplitude of $\mathrm{pdm}$ and duration of $\mathrm{tdm}$. 

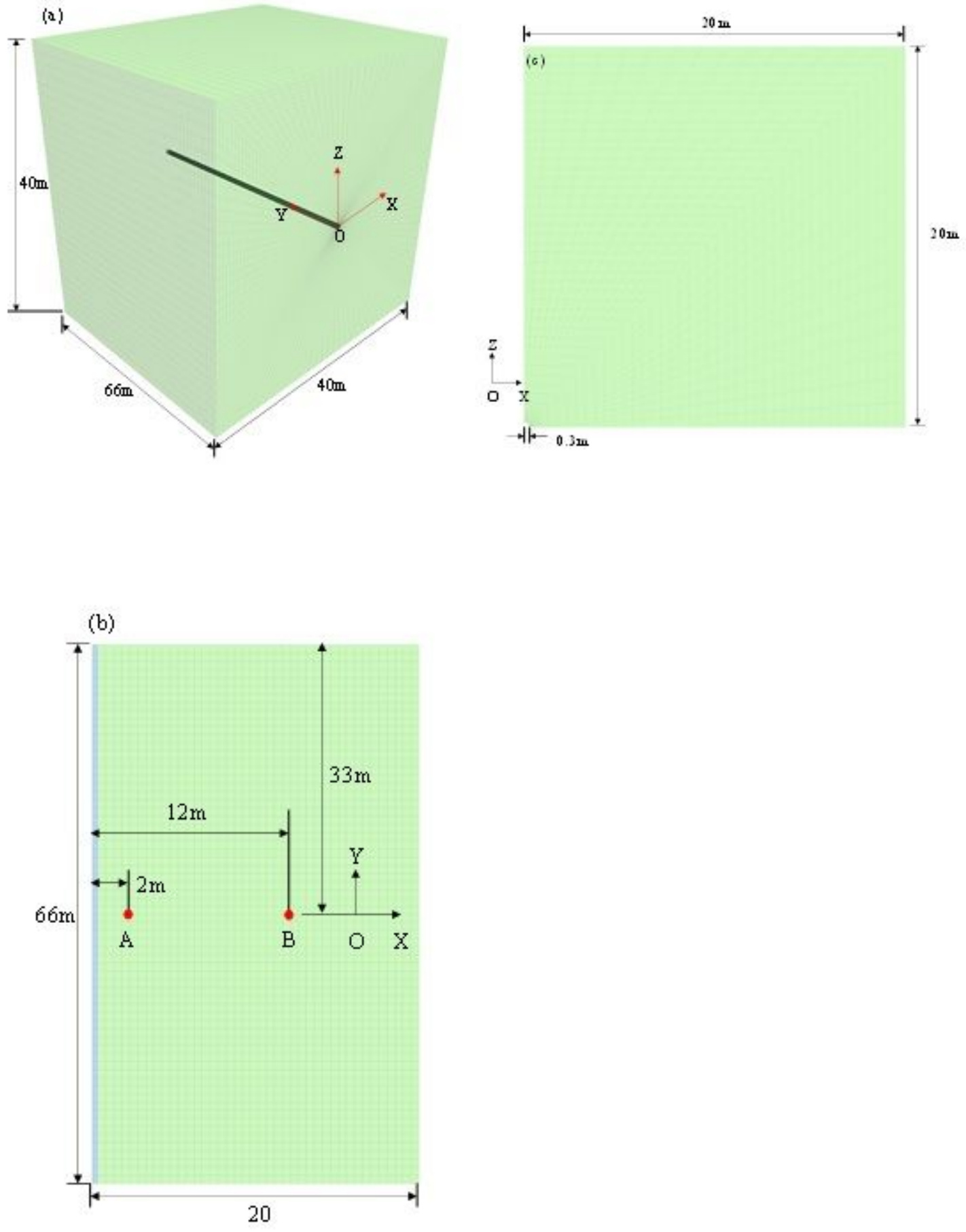

Figure 6

Numerical simulation for dynamic analysis of local damping. (a) Numerical model geometry. (b) Sectional panel of the calibrated model $(z=0)$. (c) Sectional panel of the calibrated model $(y=0)$ 


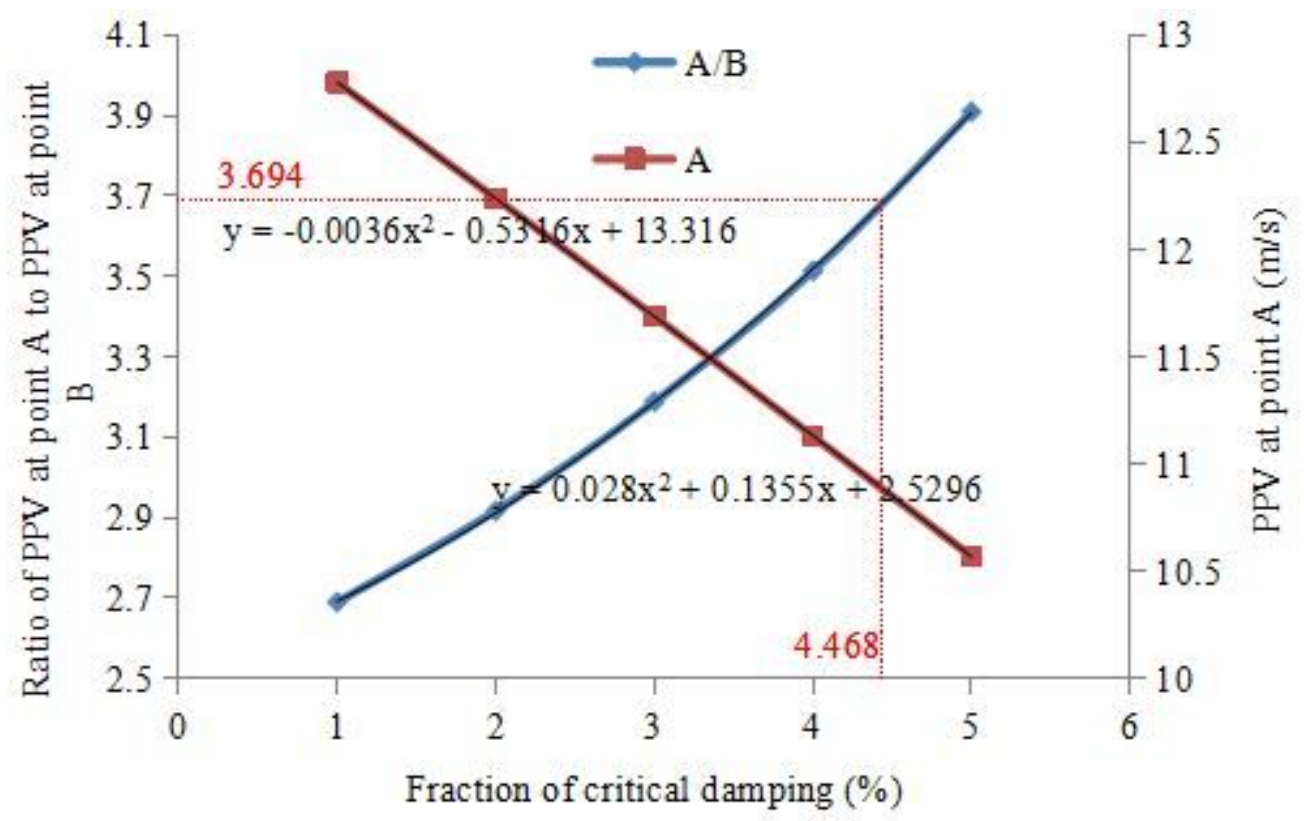

Figure 7

Graphs for calibration with respect to dynamic stress and local damping coefficient

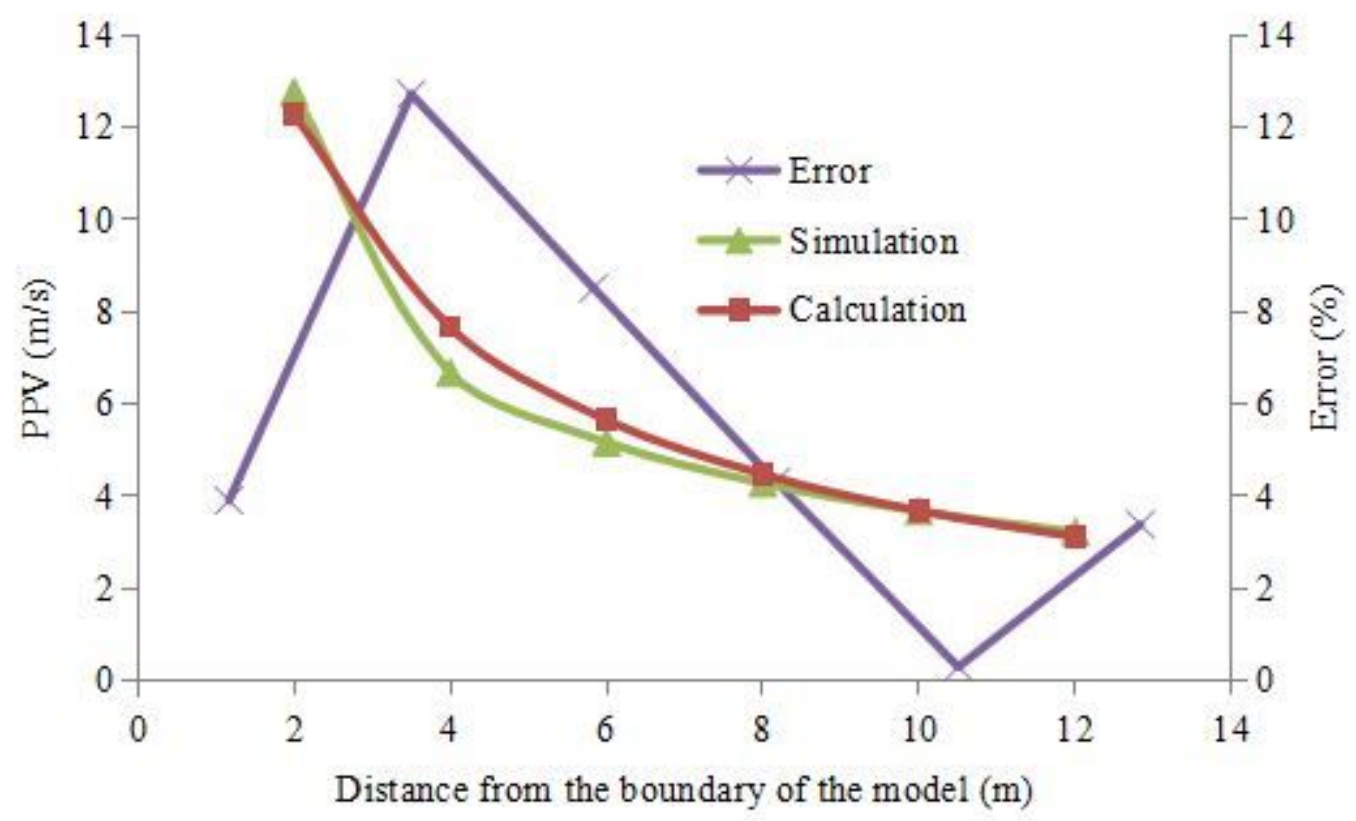

Figure 8

Error analysis of PPV with increasing distance 


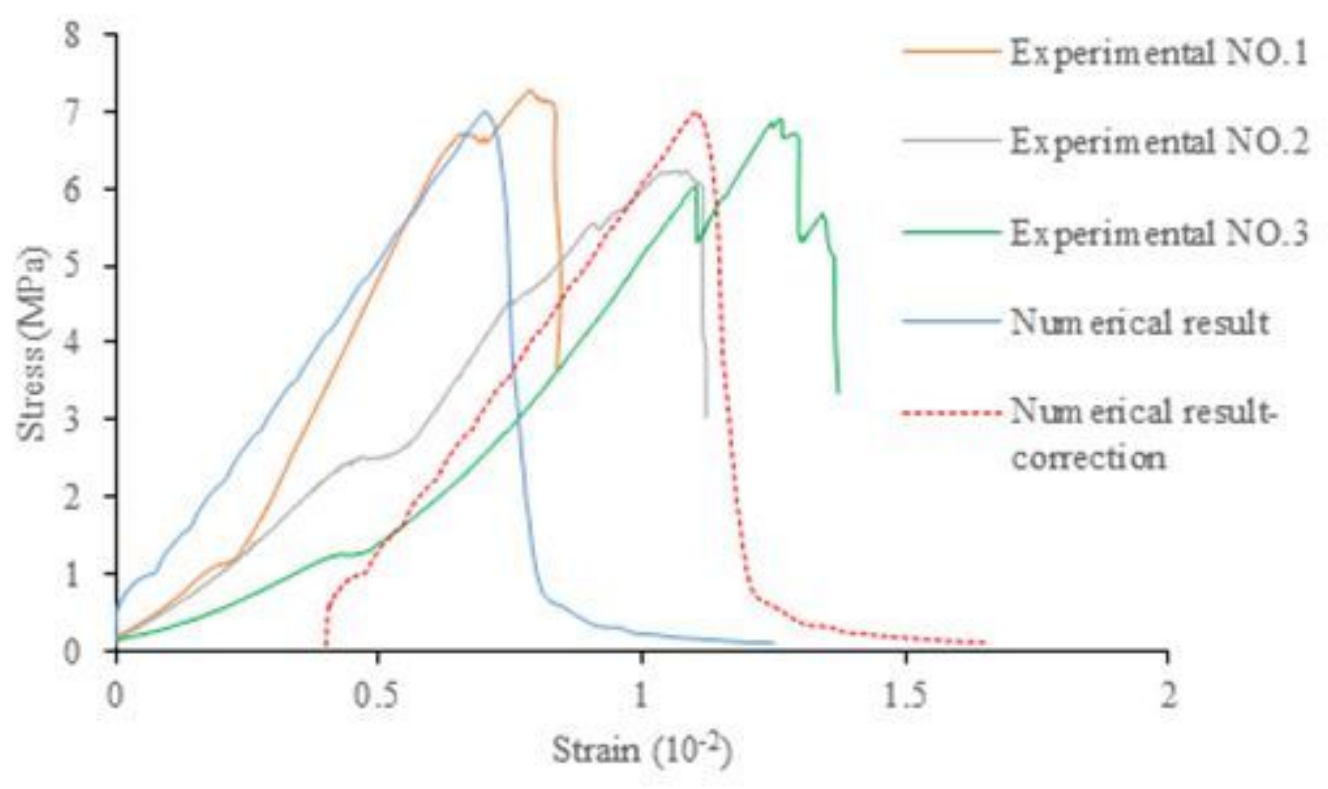

Figure 9

Stress vs strain experimental and numerical curves for coal specimens.

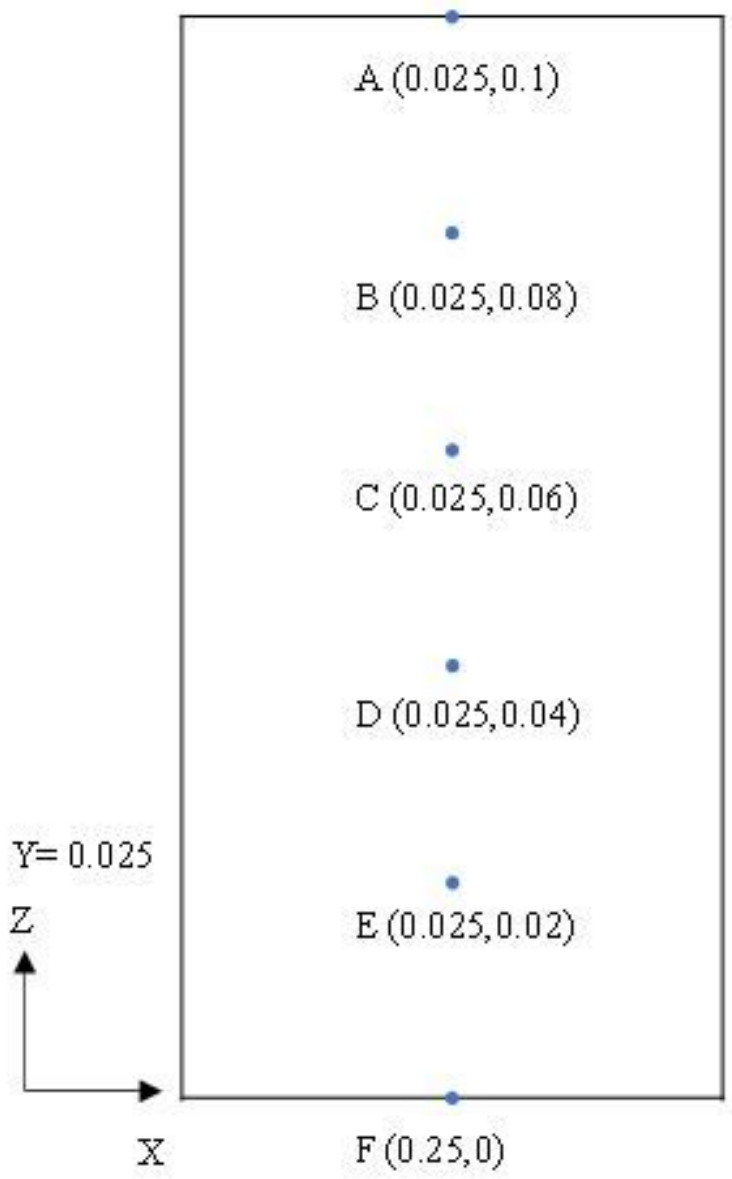

Figure 10

Cross-section of the model, in which 6 typical points where the stresses will be retrieved. 


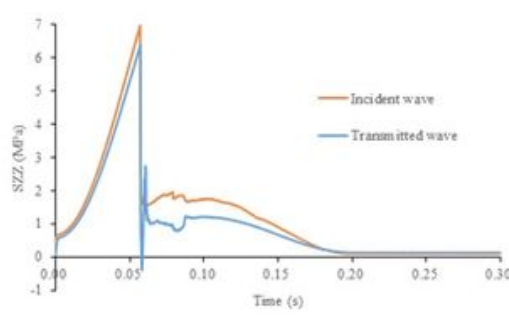

(a)

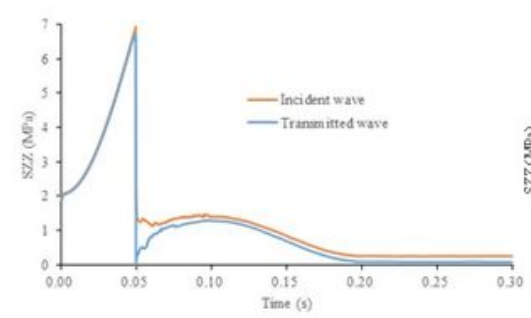

(c)

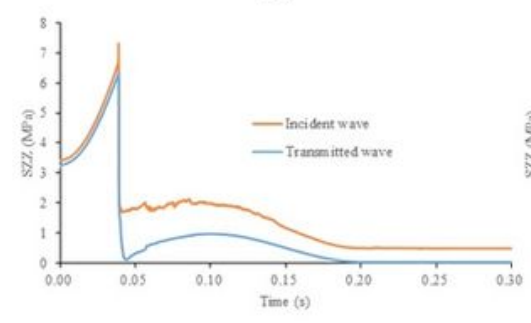

(e)

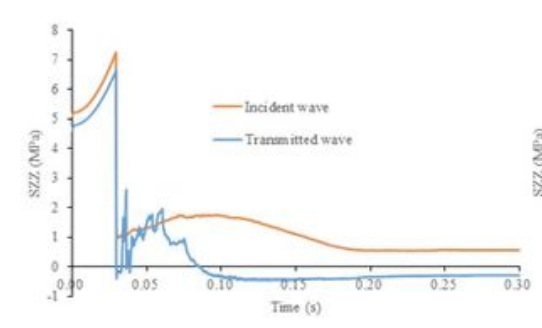

(g)

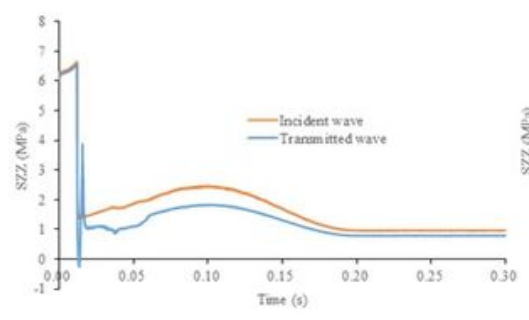

(i)

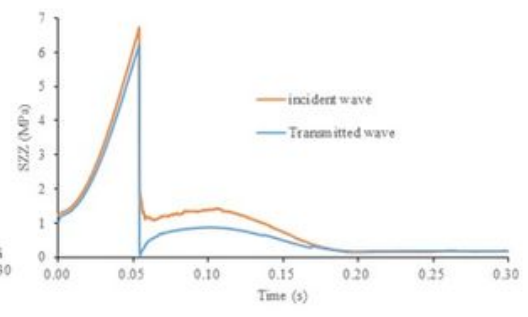

(b)

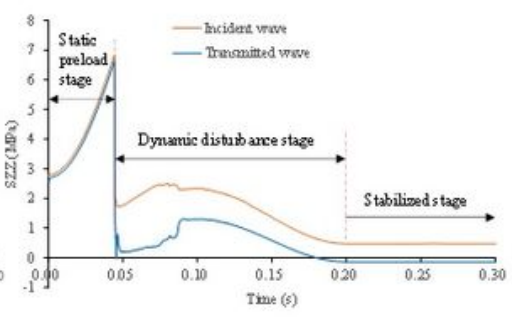

(d)

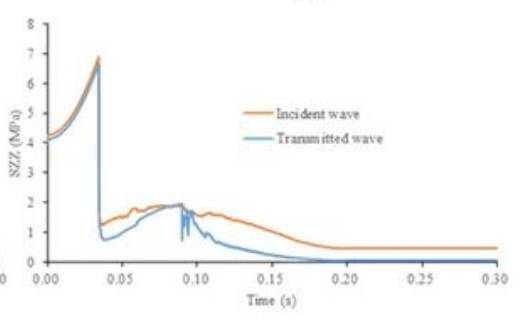

(f)

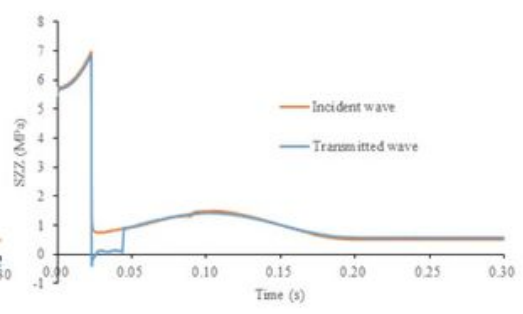

(h)

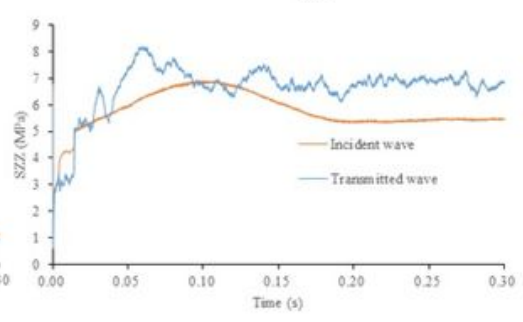

(j)

\section{Figure 11}

Waveform of the incident and transmission for the model with different LD. From Fig. 11.(a) to Fig. 11.(j), the LD is from $10 \%$ to $100 \%$, respectively. 


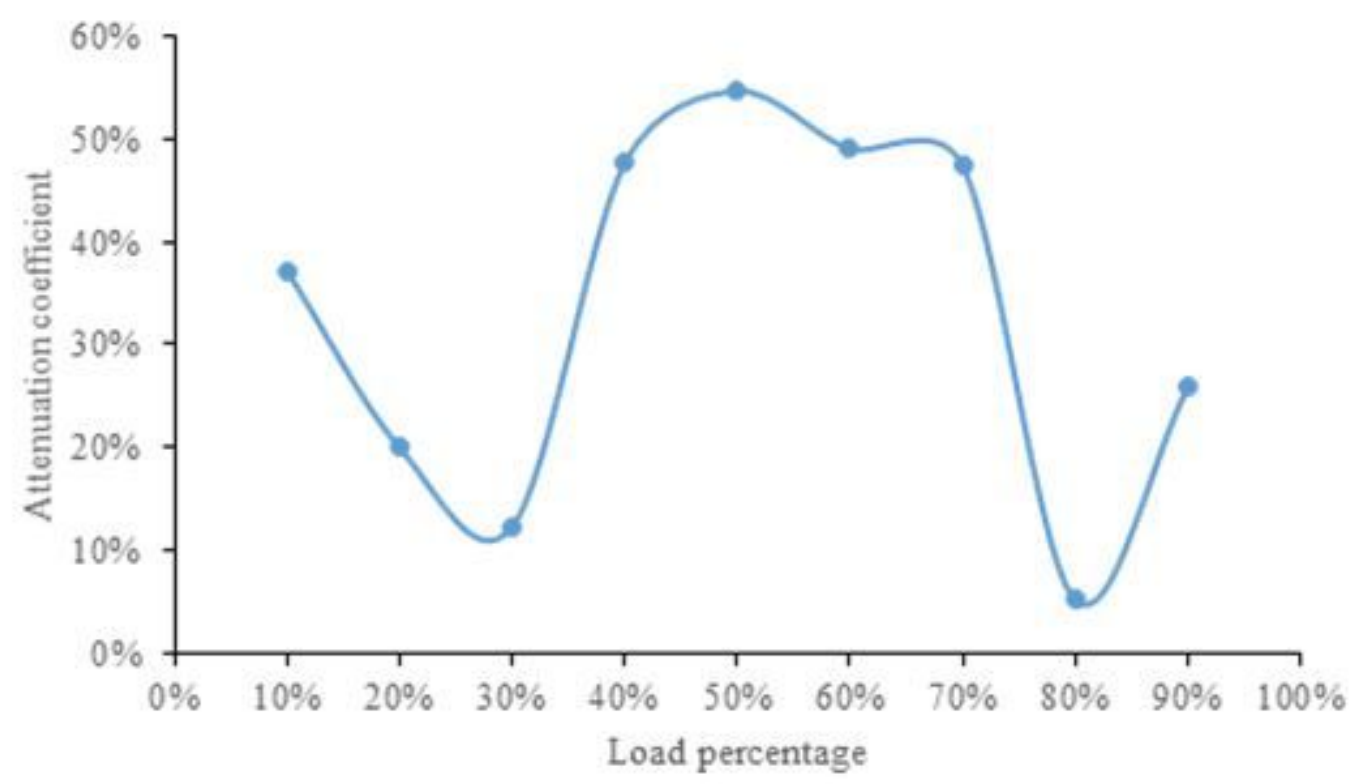

Figure 12

Attenuation coefficient versus time curve for different load percentage.

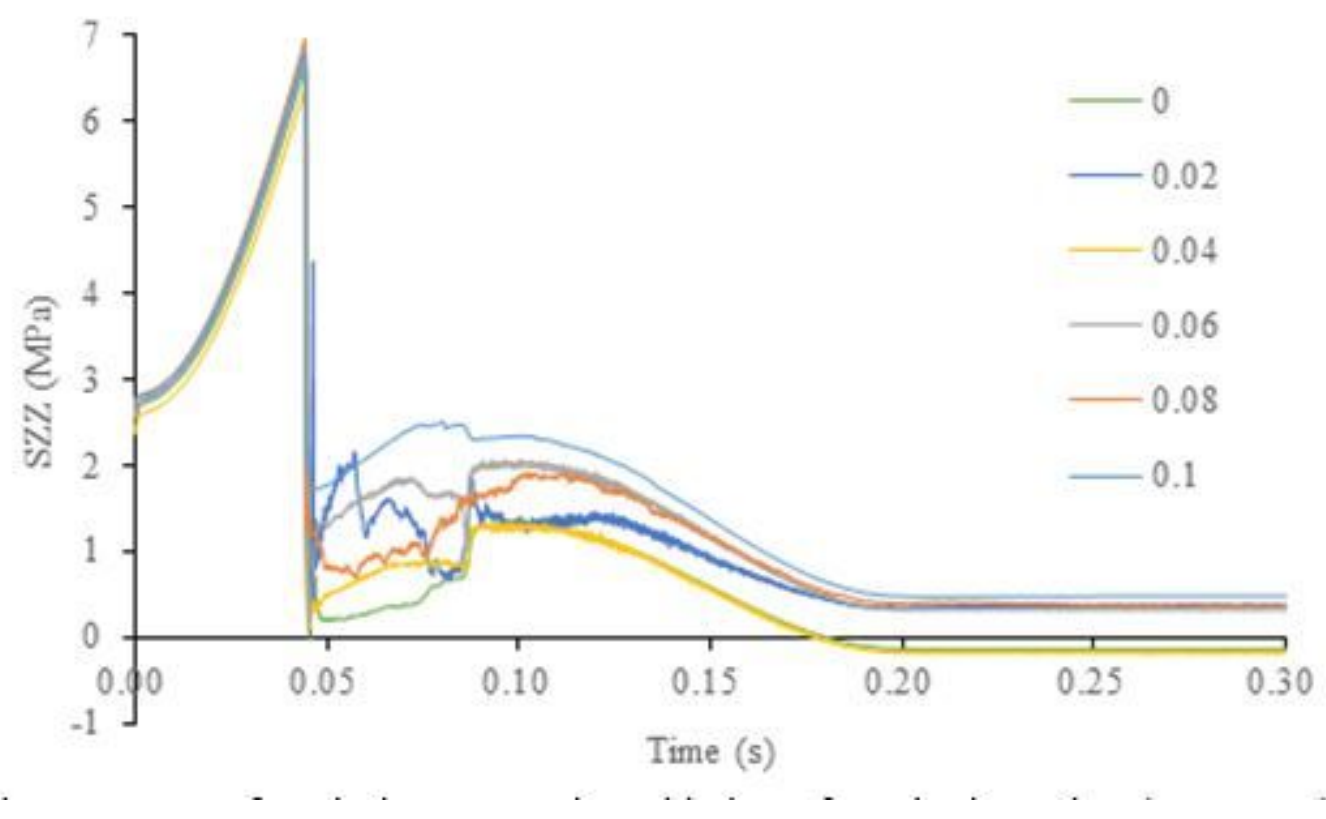

Figure 13

Curves of vertical stress varying with time of monitoring points $(L D=40 \%)$. 


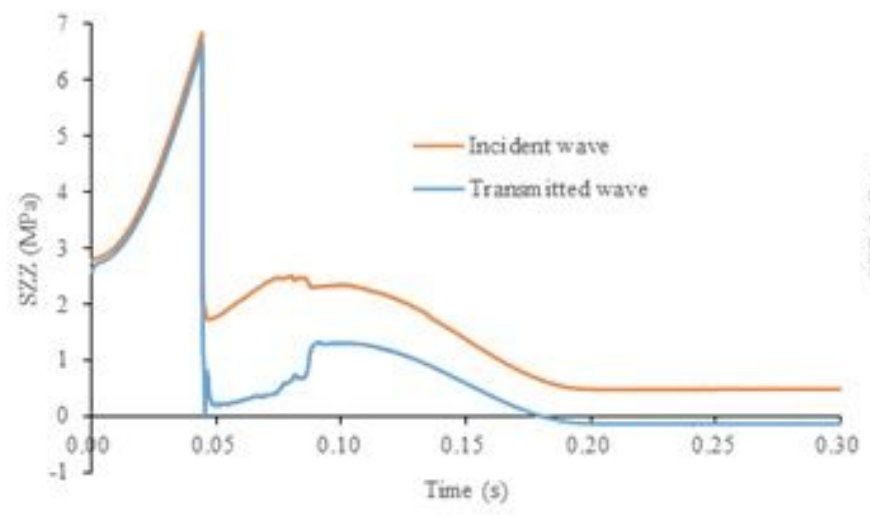

(a)

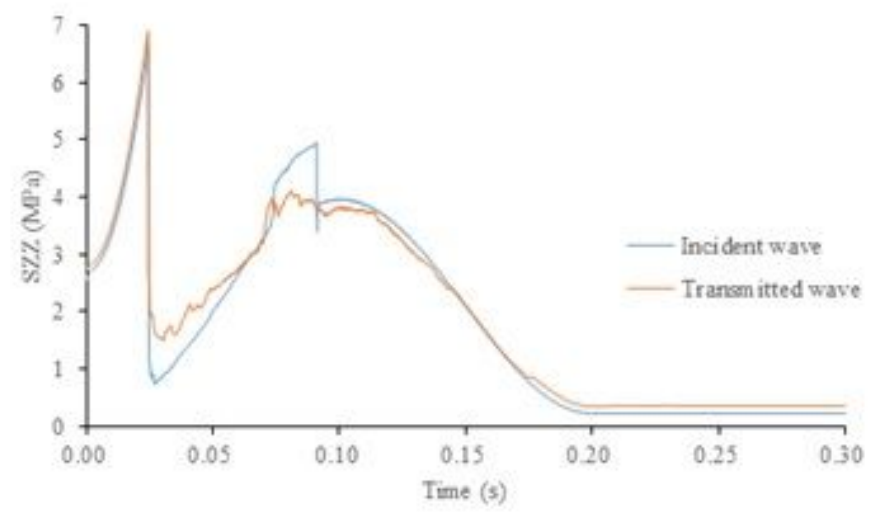

(c)

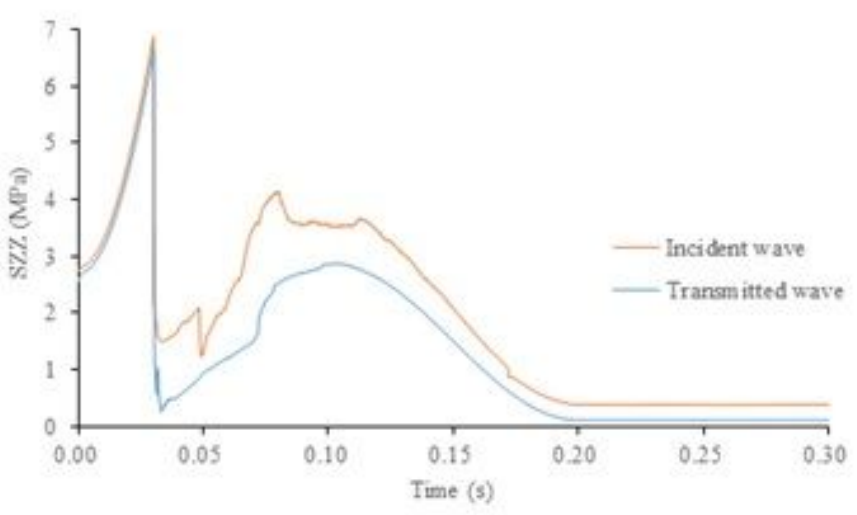

(b)

\section{Figure 14}

Vertical stress versus time curves for different dynamic disturbance intensity(load percentage $=0.4):(a)$ $10 \mathrm{MPa}$; (b) $20 \mathrm{MPa}$; (c) $30 \mathrm{MPa}$. 


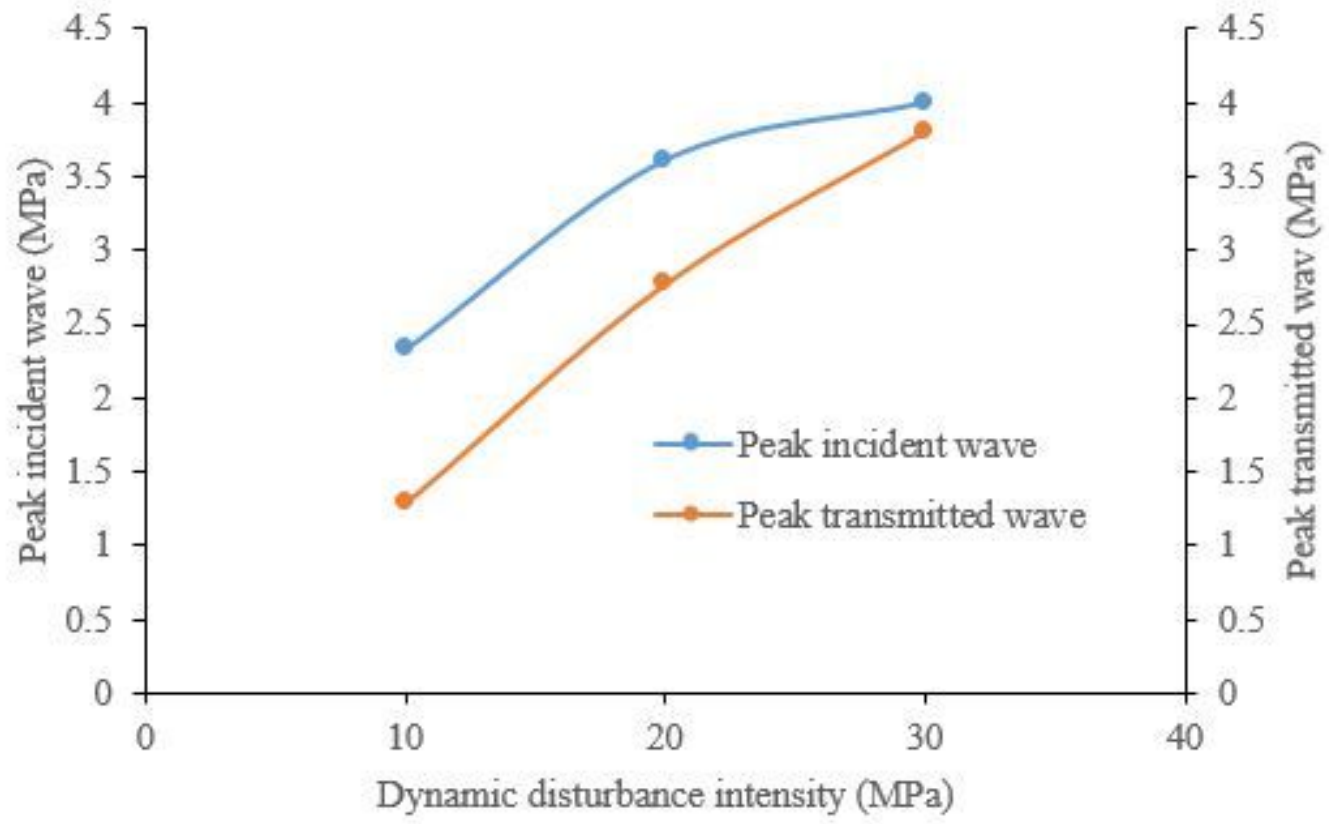

Figure 15

Effect of dynamic disturbance intensity on the peak value of incident and transmitted wave stress. 